\title{
Türkiye'de Doğrudan Yabancı Yatırım Girişleri ve Yurtiçi Yatırım İlişkisi: Doğrusal OImayan ARDL Yaklaşımı
}

Zuhal KURUL (https://orcid.org/0000-0001-9677-8260), Department of Economics, Hacettepe University, Turkey; e-mail: zkurul@hacettepe.edu.tr

\section{The Relationship Between Foreign Direct Investment Inflows and Domestic Investment in Turkey: Nonlinear ARDL Approach}

\begin{abstract}
Foreign direct investment (FDI) inflows have rapidly increased the international economic activities in developing countries since the mid-1980s. Also, FDI inflows have been considered as an important external source of productivity increase, technology transfer, and capital accumulation in these countries. Thus, it becomes important to investigate the impact of FDI inflows on domestic investment. This study analyses the relationship between FDI inflows and domestic investment in Turkey throughout 1984-2018 by employing a nonlinear ARDL approach. This study reveals an asymmetric complementary relationship between FDI inflows and domestic investment in the long run. We find that the long-run impact of a positive change (increase) in FDI inflows on domestic investment is more significant than that of a negative change (decrease). This study suggests that policymakers should formulate policies that attract more FDI inflows and improve the investment climate to increase domestic investment.
\end{abstract}

Keywords

JEL Classification Codes :
Foreign Direct Investment Inflows, Domestic Investment, Asymmetry, Nonlinear ARDL Approach.

\section{$\ddot{\mathbf{O z}}$}

Doğrudan yabancı yatırım girişleri, 1980'lerin ortalarından bu yana gelişmekte olan ülkelerde uluslararası ekonomik aktiviteleri hızla artırmaktadır. Ayrıca, doğrudan yabancı yatırım girişleri bu ülkelerde teknoloji transferinin ve sermaye birikiminin bir dış kaynağı olarak görülmektedir. Dolayısıyla doğrudan yabancı yatırım girişlerinin yurtiçi yatırımlar üzerindeki etkilerinin incelenmesi önem kazanmaktadır. Bu çalışma, doğrudan yabancı yatırım girişleri ile yurtiçi yatırımlar arasındaki ilişkiyi Türkiye için 1984-2018 dönemini kapsayan veriler kullanarak doğrusal olmayan ARDL yaklaşımı ile analiz etmektedir. Çalışmanın sonuçları, doğrudan yabancı yatırım girişleri ile yurtiçi yatırımlar arasında uzun dönemde asimetrik bir tamamlayıcılık ilişkisi olduğunu göstermektedir. Çalışmada doğrudan yabancı yatırım girişlerindeki pozitif bir değişimin (artışın) yurtiçi yatırımlar üzerindeki uzun dönem etkisinin, negatif bir değişimin (azalışın) etkisinden daha büyük olduğu bulunmuştur. $\mathrm{Bu}$ sonuçlar, yurtiçi yatırımların artırılması için politika yapıcıların yatırım ortamını iyileştiren ve doğrudan yabancı yatırımları daha çok çekmeyi sağlayan politikalar geliştirmesi gerektiğini ortaya koymaktadır. 
Kurul, Z. (2021), “Türkiye'de Doğrudan Yabancı Yatırım Girişleri ve Yurtiçi Yatırım İlişkisi: Doğrusal Olmayan ARDL Yaklaşımı”, Sosyoekonomi, 29(49), 271-292.

\section{Giriş}

Son otuz yıldır doğrudan yabancı yatırımlar, uluslararası ekonomik faaliyetler açısından büyük önem taşımaktadır. 1980'lerin ortasından itibaren hem gelişmiş hem de gelişmekte olan ülkelerde hız kazanan finansal serbestleşme hareketi, küresel doğrudan yabancı yatırımların artmasına neden olmuş ve ülkeleri doğrudan yatırımlara daha duyarlı hale getirmiştir. Çok uluslu şirketlerin hızlı bir şekilde arttığı bu serbestleşme döneminde doğrudan yabancı yatırımların ilk olarak yöneldiği ülkeler gelişmiş ülkeler olmuştur. Ancak son yıllarda gelişmekte olan ülkelerin doğrudan yabancı yatırımları çekmeye yönelik politikaları sonucunda yatırımcıların gelişmekte olan ülkeleri tercih ettiği görülmektedir.

Küresel doğrudan yabancı yatırım akımlarının 1980 sonrası hareketi incelendiğinde yatırımların büyüklüğü ve yönündeki değişimler daha açık hale gelmektedir. Örneğin, 19902008 döneminde istikrarlı bir artış sergileyen doğrudan yabancı yatırımlar, ilk büyük düşüşü 2008 Küresel Finansal Krizi ile birlikte yaşamıştır (World Bank, 2009). 2008-2009 yıllarındaki sert azalışların ardından 2014 yılında başlayan toparlanma eğilimi 2016 yılında yeniden tersine dönmüştür ve dünya genelinde doğrudan yabancı yatırım akımları azalmaya devam etmektedir. UNCTAD (2019: 1)'a göre 2018 yılında küresel doğrudan yabanc1 yatırım akımları \%13'lük bir düşüşle \$ 1,3 trilyon seviyesine gerçekleşmiştir. Akımların büyüklüğündeki azalışların yanı sıra doğrudan yabancı yatırımların yönü de değişim göstermektedir. Özellikle 2018 yılında gelişmiş ülkelere giden doğrudan yabancı yatırım akımları \%27'lik bir azalma sergileyerek 2004'ten bu yana görülen en düşük seviyeye ulaşmıştır. Gelişmiş ülkelerdeki bu durumun aksine gelişmekte olan ülkelere giden doğrudan yabancı yatırım akımları \%2'lik bir artış göstermiş ve gelişmekte olan ülkelerin küresel doğrudan yabancı yatırım akımları içindeki payı tarihsel olarak ilk kez \%54 düzeyine çıkmıştır. Bu gelişmelerin sebepleri konusundaki araştırmalar çoğunlukla ABD’deki vergi reformlarının, küresel ticaretteki gerginliklerin ve jeopolitik risklerin etkilerini işaret etmektedir. Dünya genelinde doğrudan yabancı yatırımların gerilemesi daha çok küresel olumsuzluklarla açıklanabilirken gelişmekte olan ülkelerin toplam yatırımlardan aldığı payın giderek artması ise gelişmekte olan ülkelerin bir kısmının ekonomik görünümünün olumlu ilerlemesi ve bu ülkelerin yatırım ortamını geliştirmeye yönelik gayretleri ile açıklanmaktadır (UNCTAD, 2019: 5). Tüm bu gelişmeler, doğrudan yabancı yatırımların gittiği ülkede yarattığı etkilerinin incelenmesinin önemini ortaya koymaktadır.

Gelişmekte olan ülkelerin doğrudan yabancı yatırımları kendilerine çekmek için büyük çaba sarf etmelerinin başlıca nedeni ekonomik büyüme ve verimlilik artışı yoluyla doğrudan yabancı yatırım girişlerinden maksimum faydayı sağlamaktır. $\mathrm{Bu}$ yatırımların ekonomik büyümeyi etkileme kanallarından en önemlisi fiziksel sermayenin ev sahibi ülkeye transferini sağlaması ve bu şekilde ev sahibi ülkenin sermaye oluşumuna katkı sunmasıdır. Buna ek olarak doğrudan yabancı yatırımlar, fiziksel olmayan sermaye ve varlıkların da transferini sağlamaktadır (Wang, 2010: 3711). Fiziksel olmayan varlıkların transferi bağlamında doğrudan yabancı yatırımların en büyük faydalarından biri uluslararası teknoloji transferini sağlamasıdır. Doğrudan yabancı yatırımlar, daha ileri ve yeni teknikleri ve ayrıca daha gelişmiş yönetim becerilerini gittikleri ülkelere taşımakta ve böylece yerel 
firmaların gelişmiş üretim teknolojisi bilgisinden (know-how) yararlanmalarını sağlamaktadır. Yabancı firmaların yeni ürünleri ve süreçleri yerel piyasalarla tanıştırması ve yerel firmaların bu yeni teknoloji difüzyonundan yararlanmasıyla ekonomik büyüme de desteklenmiş olmaktadır (Alfaro vd., 2004: 90). Doğrudan yabancı yatırım girişleri, özellikle katma değeri yüksek üretimin sınırlı ve zor olduğu gelişmekte olan ülkelerde yeni ve gelişmiş teknolojilerin edinilmesi ve/veya bu teknolojilere uyum sağlanması açısından teşvik edilmektedir. Doğrudan yabancı yatırımlar aynı zamanda yatırım fonlarının genişletilmesi ve akışının sağlanması ve işgücü niteliklerinin iyileştirilmesi gibi konularda gelişmekte olan ülkelerin ekonomik gündeminde yer almaktadır. Özellikle sermaye oluşumunun kalıcı olarak yetersiz olduğu birçok gelişmekte olan ülkede bu tür uzun vadeli yatırımlar, yurtiçi sermaye oluşumunun dış kaynağı olma rolünü üstlenmiş ve ekonomik kalkınmanın finansmanında bir araç haline gelmiştir (Amighini vd., 2017: 2). Bu çerçevede doğrudan yabancı yatırım girişleri ve ekonomik büyüme ilişkisine dair çalışmalar geniş bir literatür oluşturmaktadır ${ }^{1}$. Ancak doğrudan yabancı yatırım girişlerinin yurtiçi yatırımlar üzerindeki etkilerine odaklanan çalışma sayısı daha az ve bu çalışmalarda ortaya konan teorik ilişkiler çok yönlü ve daha karmaşıktır.

Teorik olarak doğrudan yabancı yatırımların yurtiçi sermaye oluşumu üzerinde iki tür etkisi vardır. Bunlardan ilkinde doğrudan yabancı yatırım girişleri yurtiçi yatırımları artırmaktadır. $\mathrm{Bu}$ etkiye doğrudan yabancı yatırımların yurtiçi yatırımları çekmesi (crowding-in) adı verilmektedir. $\mathrm{Bu}$ tür bir etkinin oluşumunda doğrudan yabancı yatırımların temel rolü, geldikleri ülkede pozitif bir teknolojik dışsallık yaratmaktır. Doğrudan yabancı yatırımlar, bilginin ve teknik uzmanlığın yatırım yapılan ülkeye transferine ve yurtiçindeki firmalar arasında teknolojinin yayılmasına neden olmakta ve bu yolla yurtiçi firmaların toplam faktör verimliliğini ve ihracat eğilimini artırmaktadır (Sun, 1998: 678). Doğrudan yabancı yatırım girişlerinin yurtiçi yatırım teşvik etmesindeki bir diğer neden ise gelen yatırımların pek çok endüstrinin kendi aralarındaki arz ve talep ilişkilerini değiştirmesidir. Örneğin çok uluslu bir şirket, yatırım yaptığ piyasasında üretime başladığında yurtiçinde üretilen ara malı talebinde bir artış olması beklenmektedir. Artan talebin karşılanması için ülkede ara malı üreten yurtiçi firma sayısının ve bu firmaların üretimlerinin artması gerekir (Lipsey, 2004: 359). Ara malı üreten firmalar arasında rekabetin arttığı bu durumda aslında bir sektördeki rekabet diğer sektördeki firmaların üretiminin artmasına yönelik olarak bir fayda yaratmaktadır. Özellikle ara mallarının fiyatlarında bir düşüş görülüyor ve firmalar ileriye dönük bağlantılar kuruyorsa müşteri konumundaki firmaların üretimini artırma potansiyeli doğmaktadır. Bunlara ek olarak, doğrudan yabancı yatırımlar yurtiçi çıktıya bir talep yarattıkları için geriye dönük bağlantılar yoluyla arz endüstrilerini güçlendirmekte ve sonuçta yurtiçi firmaların daha çok üretim yapmasını teşvik etmektedir (Markusen \& Venables, 1999: 336). Doğrudan yabancı

\footnotetext{
1 Doğrudan yabancı yatırımlar ve büyüme ilişkisi bu çalışmanın kapsamının dışında tutulduğu için ilgili literatür Borensztein vd. (1998), De Mello (1999), Mody ve Murshid (2002), Choi (2004) ve Wang ve Yu (2007) gözden geçirilerek takip edilebilir.
} 
yatırımların yurtiçi yatırımları teşvik ettiği böyle durumlarda doğrudan yabancı yatırımlar ve yurtiçi yatırımlar arasında tamamlayıcılık ilişkisi oluşmaktadır.

Doğrudan yabancı yatırımların yurtiçi yatırımlar üzerindeki olası etkilerinden ikincisi dışlama (crowding-out) etkisidir. Bu etkide doğrudan yabancı yatırım girişleri, yurtiçi yatırımların azalmasına sebep olmaktadır. Dışlama etkisi daha çok doğrudan yabancı yatırım yapan firmaların yurtiçindeki etkinliği ile ilgilidir. Ĕ̆ger göreli olarak daha etkin (bilgi, deneyim, yenilik kapasitesi, gelişmiş teknoloji ve nitelikli işgücü konularında) yabancı firmalar, üretimde yurtiçi firmaların yerini alıyorsa yurtiçi yatırımlarda bir azalma beklenmektedir. Burada yabancı firmaların piyasaya girdiklerinde daha az etkin olan yurtiçi firmaları piyasa dışına ittikleri görülür. Bu durumun toplam verimliliği artırması söz konusu olsa dahi kısa dönemde yatırımlar ve üretken kapasite üzerinde olumsuz etkiler doğurabilir (Fry, 1993: 14; Jansen, 1995: 196; Agosin \& Mayer, 2000: 151-152). Hatta yabancı firmalar piyasada baskın hale gelirlerse, piyasa rekabetçilikten uzaklaşmakta ve etkinlik azalmaktadır (Farla vd. 2014: 1). Amsden (2011: 66)'e göre dışlama etkisi daha çok kısıtlı yatırım fırsatlarının olduğu sektörlerde görülmektedir. Buna göre yatırım yapma yönünden kısıtlı firmalar piyasadan çıkmak zorunda kalmaktadırlar. Eğer dışlama etkisi söz konusu ise doğrudan yabancı yatırımlar ve yurtiçi yatırımlar arasında bir ikame ilişkisi vardır. Doğrudan yabancı yatırım girişleri ve yurtiçi yatırımlar arasındaki ilişkinin hangi yönde olduğu gelişmekte olan ülkelerin belirleyecekleri politikalar için önem taşımaktadır. Tamamlayıcılık ilişkisinin olduğu durumlarda bu ülkeler daha çok doğrudan yabancı yatırımcıları hedefleyen politikalara (yatırım anlaşmaları, tercihli vergilendirme yöntemleri, tercihli krediler vb.) yönelirken ikame ilişkisinin varlığında yurtiçi firmalar için oluşabilecek uzun dönemli maliyetlerden kaçınmaktadırlar.

Bu çalışmada Türkiye için doğrudan yabancı yatırım girişleri ve yurtiçi yatırımlar arasında bir tamamlayıcılık ya da ikame ilişkisinin olup olmadığı incelenmiştir. Çalışma, Chang (2010)'un doğrudan yabancı yatırım girişlerinin yurtiçi yatırımları doğrusal olmayan bir uyum mekanizması ile etkileyebileceği varsayımından hareket ederek Türkiye için doğrudan yabancı yatırım girişleri ve yurtiçi yatırımlar arasındaki olası uzun dönemli ilişkinin belirlenmesinde Shin vd. (2014) tarafından geliştirilen doğrusal olmayan ARDL (NARDL) yöntemine başvurmuştur. Bu yöntem yardımıyla literatürdeki diğer çalışmalardan farklı olarak yurtiçi yatırımların doğrudan yabancı yatırım girişlerindeki pozitif ve negatif değişimlere (artış ve azalışlara) verebileceği olası asimetrik tepkiler dikkate alınmış olmaktadır. Ayrıca bu çalışma, güncel bir veri seti ile 2002 sonrası doğrudan yabancı yatırımlardaki hızlı artış döneminin etkilerini incelemiş olmaktadır. Bu çalışmadan elde sonuçların doğrudan yabancı yatırımların uzun ve kısa dönemde yurtiçi yatırımlar üzerindeki etkilerin daha iyi anlaşılmasına ve yeni politikaların belirlenmesine katkıda bulunacağ1 düşünülmektedir.

Çalışmanın bundan sonraki ikinci bölümünde ampirik literatür gözden geçirilmektedir. Üçüncü bölümde doğrudan yabancı yatırım girişlerinin ve yurtiçi yatırımların Türkiye'deki gelişimi hakkında bilgi verilmektedir. Dördüncü bölümde çalışmada kullanılan yöntem ve veriler açıklanmakta ve beşinci bölümde ampirik bulgular 
Kurul, Z. (2021), “Türkiye'de Doğrudan Yabancı Yatırım Girişleri ve Yurtiçi Yatırım

İlișkisi: Doğrusal Olmayan ARDL Yaklașımı”, Sosyoekonomi, 29(49), 271-292.

sunulmaktadır. Sonuç bölümünde ise edilen sonuçlar değerlendirilmekte ve politika önerilerine yer verilmektedir.

\section{Ampirik Literatür}

Ampirik literatürde doğrudan yabancı yatırımlar ile yurtiçi yatırımlar arasında ilişkinin tamamlayıcı mı yoksa ikame mi olduğuna ilişkin birçok çalışma vardır ancak bu çalışmaların bulguları kesin bir sonuca işaret etmemektedir. Ampirik literatürde yer alan başlıca çalışmalar Tablo 1'de gösterilmiştir. Tablo 1 incelendiğinde Borensztein vd. (1998), Bosworth vd. (1999), De Mello (1999), Kim ve Seo (2003), Ndikumana ve Verick (2008), Tang vd. (2008), Ramirez (2010), Chang (2010), Al-Sadig (2013), Farla vd. (2014) çalışmalarının doğrudan yabancı yatırımlar ve yurtiçi yatırımlar arasında tamamlayıcılık ilişkisinin olduğu sonucuna ulaştığı görülmektedir. Bir başka ifadeyle, bu çalışmalarda doğrudan yabancı yatırımlar, yurtiçi yatırımları dışlamamaktadır. Tablo 1 'de tamamlayıcılık ilişkisinin aksine ikame ilişkinin varlığına dair kanıtlara ulaşan çalışmalar da yer almaktadır. Fry (1993), Agosin ve Mayer (2000), Misun ve Tomsik (2002), Titarenko (2005), Wang (2010) ve Morrissey ve Udomkerdmongkol (2012) doğrudan yabancı yatırımların yurtiçi yatırımlar üzerinde negatif etkileri olduğunu bularak iki değişken arasındaki ilişkinin ikame olduğunu ve doğrudan yabancı yatırımların yurtiçi yatırımları dışladığını göstermişlerdir. Sağlam ve Yalta (2011) ise doğrudan yabancı yatırımlar ile kamu ve özel yurtiçi yatırımlar arasında anlamlı bir ilişki olmadığı sonucuna ulaşmışlardır.

Tablo 1'den görüleceği üzere, sonuçlar kullanılan yöntem ve ülke grubuna göre değişkenlik göstermektedir. Çalışmaların büyük çoğunluğu doğrudan yabancı yatırım girişlerinin hem teknoloji transferinin hem de diş finansmanın bir kaynağı olarak görüldüğü gelişmekte olan ülkeler için yapılmıştır. Ancak ülkeler arasındaki farklılıklar dikkat çekmektedir (Fry, 1993; Agosin \& Mayer, 2000; Apergis vd., 2006; Adams, 2009). Apergis vd. (2006) ve Adams (2009)' e göre doğrudan yabancı yatırımların yurtiçi yatırımlar üzerindeki etkisi, yatırım çeken ülkenin gelişmişlik düzeyine ya da bölgesel yerine göre değişiklik gösterebilmektedir. Örneğin, Asya ve Afrika'daki gelişmekte olan ülkelerde doğrudan yabancı yatırımların yurtiçi yatırımları teşvik ettiğine dair elde edilen bulgular olduğu gibi özellikle Avrupa'nın gelişmiş ülkelerinde dışlama etkisinin daha belirgin olduğuna dair kanıtlar da bulunmaktadır (Apergis vd., 2006). Ayrıca ampirik bulguların bir kısmı, doğrudan yabancı yatırımların sermaye oluşumu üzerindeki etkilerinin eğitim düzeyi ve nitelikli işgücüne (Borenzstein vd., 1998), yabancı firmalar ile yurtiçi firmalar arasındaki teknoloji açı̆̆ına (De Mello, 1999), yönetişim kalitesine (Morrissey \& Udomkerdmongkol, 2012) ve yabancı firmaların üretim yaptıkları sektöre (Amighini vd., 2017) göre değişsebileceğine işaret etmektedir.

Türkiye için yapılan çalışmalar incelendiğinde bu konu ile ilgili olan çalışmaların sayısının oldukça sınırlı olduğu görülmektedir. Bu çalışmaların birçoğu (Eroğlu \& Hudson, 1997; Güven, 2001; İnsel \& Sungur, 2003; Kara \& Kar, 2005; Bayar, 2014) doğrudan yabancı yatırımların birçok makroekonomik gösterge üzerindeki etkisini bir arada inceleyen çalışmalardır. Bu çalışmalardan elde edilen ampirik bulgular, doğrudan yabancı yatırımlar 
ve yurtiçi sermaye oluşumu ilişkisinin yönü ve işareti konusunda bir fikir birliği olmadığını göstermektedir. Eroğlu ve Hudson (1997), İnsel ve Sungur (2003), Kara ve Kar (2005) ve Bayar (2014) doğrudan yabancı yatırımlar ve yurtiçi yatırımlar arasında pozitif yönlü bir ilişkinin var olduğunu öne sürerken Güven (2001) negatif yönlü bir ilişkinin geçerli olduğu sonucuna ulaşmaktadır. Türkiye özelindeki çalışmalar arasında yalnızca doğrudan yabancı yatırımların yurtiçi yatırımlar (kamu ve özel yatırımlar) üzerindeki dinamik etkileşime odaklanan tek çalışma Sağlam ve Yalta (2011)'dir. Sağlam ve Yalta (2011), VAR analizi sonuçlarına dayanarak doğrudan yabancı yatırımlar ile özel ve kamu yatırımları arasında anlamlı bir ilişki olmadı̆̆ı sonucuna ulaşmışlardır.

Ampirik literatürde dikkat çeken bir diğer nokta, çalışmaların büyük çoğunluğunun doğrudan yabancı yatırımlar ile yurtiçi yatırımlar arasında örtük bir doğrusal ilişki olduğu varsayımına dayanmasıdır. Bu varsayım altında yurtiçi yatırımlar, doğrudan yabancı yatırımlardaki pozitif ve negatif sapmalara aynı tepkiyi vermektedir. Chang (2010) ise Kottaridi ve Stengos (2010) ve Jyun-Yi ve Chig-Chiang (2008)'in doğrudan yabanc1 yatırımların ekonomik büyümeyi doğrusal olmayan bir uyum mekanizması ile etkilediğini öne süren çalışmalarından yola çıkarak bu örtük varsayımın geçerli olmadığını göstermeye çalışmıştır. Chang (2010)'un elde ettiği bulgulara göre doğrudan yabancı yatırımlardaki pozitif ve negatif sapmalar, yurtiçi yatırımları ve ekonomik büyümeyi farklı düzeylerde etkilemektedir. Literatürde doğrudan yabancı yatırımlar ve yurtiçi yatırımlar arasında doğrusal olmayan bir ilişkinin var olabileceğine yönelik bir yaklaşımın gelişmiş olması, Türkiye için tamamlayıcılık ya da ikame ilişkisinin doğrudan yabancı yatırım girişlerinin pozitif ve negatif değişimlerine göre değişebileceğinin ortaya konması ve uygulanacak doğrudan yabancı yatırım politikalarına yol göstermesi açısından önem taşımaktadır ${ }^{2}$.

$\mathrm{Bu}$ çalışmada, ampirik literatürdeki son gelişmeler dikkate alınarak Türkiye için doğrudan yabancı yatırım girişlerindeki pozitif ve negatif değişimlerin yurtiçi yatırımların düzeyini farklı büyüklüklerde etkileyebileceği dikkate alınmaktadır. Dolayısıyla bu çalışma, doğrudan yabancı yatırımların tamamlayıcılık ya da ikame özelliklerinin asimetrik bir ilişkiyle belirlenebileceği yöntemlere başvurmaktadır.

\section{Tablo: 1}

\section{Doğrudan Yabancı Yatırımların Yurtiçi Yatırımlar Üzerindeki Etkilerine Yönelik Literatür}

\begin{tabular}{|l|l|l|l|}
\hline Çalışma & Örneklem & Yöntem & Temel Bulgular \\
\hline $\begin{array}{l}\text { Fry } \\
(1993)\end{array}$ & $\begin{array}{l}\text { 16 gelişmekte olan } \\
\text { ülke, 1966-1988 }\end{array}$ & $\begin{array}{l}\text { Panel veri analizi- } \\
\text { panel OLS }\end{array}$ & $\begin{array}{l}\text { Tüm örneklem dikkate alındığında doğrudan yabanc1 yatırımlar ile yurtiçi } \\
\text { yatırımlar arasındaki ilişki negatiftir. Asya-Pasifik bölgesindeki beş ülke için } \\
\text { analiz tekrarlandığında ise doğrudan yabancı yatırımlar yurtiçi yatırımları } \\
\text { pozitif yönde etkilemektedir. }\end{array}$ \\
\hline $\begin{array}{l}\text { Borensztein vd. } \\
(1998)\end{array}$ & $\begin{array}{l}69 \text { gelişmekte olan } \\
\text { ülke, 1970-1989 }\end{array}$ & $\begin{array}{l}\text { Panel veri analizi- } \\
\text { SUR model }\end{array}$ & $\begin{array}{l}\text { Doğrudan yabanc1 yatırım girişleri ile yurtiçi yatırımlar arasında pozitif yönlü } \\
\text { bir ilişki vardır. Net doğrudan yabancı yatırım girişlerindeki \%1'lik bir artış } \\
\text { yurtiçi yatırımları \%1'den daha fazla artırmaktadır. }\end{array}$ \\
\hline
\end{tabular}

2 Literatürde Türkiye'de uygulanabilecek doğrudan yabancı yatırım politikalarına yönelik olarak önemli ampirik sonuçlara ulaşan çalışmalar için bkz. Erdal ve Tatoğlu (2002), Sayek (2007), Karagöz (2007). Ayrıca, Türkiye'de doğrudan yabancı yatırımlar ile çeşitli makroekonomik ve sosyal/politik olaylar arasındaki ilişkileri özellikle doğrusal olmayan modellerle inceleyen çallşmalar için bkz. Bilgili vd. (2012) ve Omay vd. (2013). 
Kurul, Z. (2021), “Türkiye'de Doğrudan Yabancı Yatırım Girişleri ve Yurtiçi Yatırım İlișkisi: Doğrusal Olmayan ARDL Yaklaşımı”, Sosyoekonomi, 29(49), 271-292.

\begin{tabular}{|c|c|c|c|}
\hline $\begin{array}{l}\text { Bosworth vd. } \\
\text { (1999) }\end{array}$ & $\begin{array}{l}59 \text { gelişmiş ve } \\
\text { gelişmekte olan } \\
\text { ülke, } 1979-1995\end{array}$ & $\begin{array}{l}\text { Panel veri analizi - } \\
\text { OLS-IV }\end{array}$ & $\begin{array}{l}\text { Doğrudan yabancı yatırım girişleri ile yurtiçi yatırımlar arasında pozitif yönlü } \\
\text { bir ilişki vardır. Doğrudan yabancı yatırımların yurtiçi yatırımlar üzerindeki } \\
\text { etkisi diğer sermaye akımlarına göre (portföy yatırımları ve borç akımları) } \\
\text { daha büyüktür. }\end{array}$ \\
\hline $\begin{array}{l}\text { De Mello } \\
(1999)\end{array}$ & $\begin{array}{l}17 \text { gelişmiş ülke ve } \\
20 \text { gelişmekte olan } \\
\text { ülke, } 1970-1990\end{array}$ & $\begin{array}{l}\text { Zaman serisi analizi } \\
\text { (eş bütünleşme) ve } \\
\text { panel veri sabit etkiler } \\
\text { modeli }\end{array}$ & $\begin{array}{l}\text { Doğrudan yabancı yatırımlar ile yurtiçi yatırımlar arasındaki tamamlayıcılık } \\
\text { ilişkisi daha çok gelişmekte olan ülkeler arasında görülmektedir. İkame ilişkisi } \\
\text { ise gelişmişülkeler için tespit edilmiştir. }\end{array}$ \\
\hline $\begin{array}{l}\text { Misun } \\
\& \text { Tomsik } \\
(2002)\end{array}$ & $\begin{array}{l}\text { Çek Cumhuriyeti, } \\
\text { Polonya ve } \\
\text { Macaristan, 1990- } \\
2000\end{array}$ & Zaman serisi analizi & $\begin{array}{l}\text { Çek Cumhuriyeti ve Macaristan için doğrudan yabancı yatırımlar, yurtiçi } \\
\text { yatırımları pozitif yönde etkilerken Polonya için ilişki negatif yönlüdür. }\end{array}$ \\
\hline $\begin{array}{l}\text { Kim \& Seo } \\
(2003)\end{array}$ & Kore, 1985-1999 & $\begin{array}{l}\text { Zaman serisi analizi- } \\
\text { VAR modeli }\end{array}$ & $\begin{array}{l}\text { Doğrudan yabancı yatırımlar ve büyüme ve yurtiçi yatırımlar arasındaki } \\
\text { dinamik ilişkide doğrudan yabancı yabancı yatırımlar yurtiçi yatırımları pozitif } \\
\text { yönde etkilemektedir. }\end{array}$ \\
\hline $\begin{array}{l}\text { Agosin } \\
\& \text { Machado } \\
(2005)\end{array}$ & $\begin{array}{l}32 \text { gelişmekte olan } \\
\text { ülke, } 1970-1996\end{array}$ & $\begin{array}{l}\text { Panel veri analizi, } \\
\text { Pooled OLS ve SUR } \\
\text { modeli }\end{array}$ & $\begin{array}{l}\text { Asya gelişmekte olan ülkelerinde doğrudan yabancı yatırımlar ve yurtiçi } \\
\text { yatırımlar arasında pozitif yönde bir ilişki vardır. Latin Amerika gelişmekte } \\
\text { olan ülkelerinde doğrudan yabancı yatırımlar, yurtiçi yatırımları negatif yönde } \\
\text { etkilemektedir. Afrika gelişmekte olan ülkeleri için iki değişken arasındaki } \\
\text { ilişki pozitif ve birebirdir. }\end{array}$ \\
\hline $\begin{array}{l}\text { Apergis vd. } \\
(2006)\end{array}$ & 30 ülke, 1992-2002 & $\begin{array}{l}\text { Panel veri analizi- } \\
\text { panel eş bütünleşme } \\
\text { modeli }\end{array}$ & $\begin{array}{l}\text { Doğrudan yabancı yatırımlar ve yurtiçi yatırımlar arasında anlamlı bir iki } \\
\text { yönlü ilişki vardır. Doğrudan yabancı yatırımlar yurtiçi yatırımları pozitif } \\
\text { yönde etkilemektedir. Bu pozitif ilişki özellikle Asya ve Afrika ülkeleri için } \\
\text { daha güçlüdür. Amerika ve Avrupa bölgesindeki ülkeler için ise çok değişkenli } \\
\text { modellerde dışlama etkisine dair kanıtlar elde edilmiştir. }\end{array}$ \\
\hline $\begin{array}{l}\text { Ndikumana } \\
\text { \& Verick } \\
(2008)\end{array}$ & $\begin{array}{l}38 \text { Sahra-altı Afrika } \\
\text { ülkesi, } 1970-2005\end{array}$ & $\begin{array}{l}\text { Panel veri analizi- } \\
\text { Panel sabit etkiler } \\
\text { modeli }\end{array}$ & $\begin{array}{l}\text { Doğrudan yabancı yatırım girişleri ile yurtiçi yatırımlar arasında iki yönlü bir } \\
\text { ilişki vardır. Doğrudan yabancı yatırımlar özel yurtiçi yatırımları pozitif yönde } \\
\text { etkilediği gibi yurtiçi yatırımlar da doğrudan yabancı yatırımları pozitif yönde } \\
\text { etkilemektedir. }\end{array}$ \\
\hline $\begin{array}{l}\text { Tang vd. } \\
(2008)\end{array}$ & Çin, 1988-2003 & $\begin{array}{l}\text { Zaman Serisi Analizi- } \\
\text { VAR ve ECM tahmini }\end{array}$ & $\begin{array}{l}\text { Doğrudan yabancı yatırımlar, ekonomik büyüme ve yurtiçi yatırımlar } \\
\text { arasındaki dinamik ilişkide doğrudan yabancı yatırımlar yurtiçi yatırımlar } \\
\text { üzerinde pozitif yönlü bir etkiye sahiptir. Yurtiçi yatırımların ve ekonomik } \\
\text { büyümenin doğrudan yabancı yatırımlar üzerinde anlamlı bir etkisi yoktur. }\end{array}$ \\
\hline $\begin{array}{l}\text { Adams } \\
(2009)\end{array}$ & $\begin{array}{l}30 \text { Sahra-altı Afrika } \\
\text { ülkesi, 1990-2003 }\end{array}$ & $\begin{array}{l}\text { Panel veri analizi- } \\
\text { panel OLS ve sabit } \\
\text { etkiler modeli }\end{array}$ & $\begin{array}{l}\text { Doğrudan yabancı yatırımlar ve yurtiçi yatırımlar arasında negatif ilişki vardır. } \\
\text { Bu negatif ilişki, doğrudan yabancı yatırımlar ve ekonomik büyüme arasında } \\
\text { tespit edilen pozitif ilişkinin daha toplam faktör verimliliğinin artışından } \\
\text { kaynaklandığının bir göstergesidir. }\end{array}$ \\
\hline $\begin{array}{l}\text { Wang } \\
(2010)\end{array}$ & 50 ülke, 1970-2004 & $\begin{array}{l}\text { Panel veri analizi- } \\
\text { sabit, rassal etkiler ve } \\
\text { GMM yöntemi }\end{array}$ & $\begin{array}{l}\text { Doğrudan yabancı yatırım girişleri yurtiçi yatırımları kısa dönemde negatif } \\
\text { yönde etkilemektedir ancak doğrudan yabancı yatırımların kümülatif etkisi } \\
\text { pozitiftir. Az gelişmiş ülkelerde doğrudan yabancı yatırımların kısa dönem } \\
\text { etkisi negatif; kümülatif etkisi nötrdür. }\end{array}$ \\
\hline $\begin{array}{l}\text { Chang } \\
(2010)\end{array}$ & Tayvan, 1981-2008 & $\begin{array}{l}\text { Zaman serisi analizi- } \\
\text { TAR ve MTAR } \\
\text { modeli }\end{array}$ & $\begin{array}{l}\text { Doğrudan yabancı yatırımlar, yurtiçi yatırımları artırmaktadır. Doğrudan } \\
\text { yabancı yatırımlar ile ekonomik büyüme arasındaki uzun dönemli ilişki } \\
\text { asimetriktir. }\end{array}$ \\
\hline $\begin{array}{l}\text { Ramirez } \\
(2010)\end{array}$ & $\begin{array}{l}9 \text { Latin Amerika } \\
\text { ülkesi, 1980-2002 }\end{array}$ & $\begin{array}{l}\text { Panel veri analizi, } \\
\text { panel eş bütünleşme } \\
\text { ve FMOLS modeli }\end{array}$ & $\begin{array}{l}\text { Doğrudan yabancı yatırımlar ile yurtiçi yatırımlar arasında uzun dönemli ve } \\
\text { pozitif yönlü bir ilişki vardır. Doğrudan yabancı yatırımlar, sabit sermaye } \\
\text { oluşumunun finansmanında önem büyük önem taşımaktadır. }\end{array}$ \\
\hline $\begin{array}{l}\text { Sağlam } \\
\& \text { Yalta } \\
(2011)\end{array}$ & Türkiye, 1970-2009 & $\begin{array}{l}\text { Zaman serisi analizi- } \\
\text { VAR modeli }\end{array}$ & $\begin{array}{l}\text { Doğrudan yabancı yatırımlar ile hem özel hem de kamu yatırımları arasında } \\
\text { anlamlı bir ilişki bulunmamaktadır. }\end{array}$ \\
\hline $\begin{array}{l}\text { Morrissey \& } \\
\text { Udomkerdmongkol } \\
(2012)\end{array}$ & $\begin{array}{l}46 \text { gelişmekte olan } \\
\text { ülke, 1996-2009 }\end{array}$ & $\begin{array}{l}\text { Panel veri analizi- } \\
\text { fark-GMM modeli }\end{array}$ & $\begin{array}{l}\text { Doğrudan yabancı yatırımlar yurtiçi yatıımları dışlamaktadır. Dışlama etkisi } \\
\text { yönetişim kalitesi daha iyi olan ülkelerde daha yüksektir. }\end{array}$ \\
\hline $\begin{array}{l}\text { Al-Sadig } \\
(2013)\end{array}$ & 121 ülke, 1990-2010 & $\begin{array}{l}\text { Panel veri analizi- } \\
\text { Panel OLS ve sistem- } \\
\text { GMM }\end{array}$ & $\begin{array}{l}\text { Doğrudan yabancı yatırım girişleri ve yurtiçi yatırımlar arasında pozitif yönlü } \\
\text { bir ilişki vardır. Doğrudan yabancı yatırım girişlerinin pozitif etkisi gelişmekte } \\
\text { olan ülke grubu için daha yüksektir. }\end{array}$ \\
\hline $\begin{array}{l}\text { Farla vd. } \\
(2014)\end{array}$ & $\begin{array}{l}46 \text { gelişmekte olan } \\
\text { ülke }\end{array}$ & $\begin{array}{l}\text { Panel veri analizi, } \\
\text { sistem GMM }\end{array}$ & $\begin{array}{l}\text { Doğrudan yabancı yatırım girişleri ve yurtiçi yatırımlar arasında pozitif yönlü } \\
\text { bir ilişki vardır. Kurumsal gelişmişlik ve doğrudan yabancı yatırımların } \\
\text { etkileşimi ise yurtiçi yatırımlar üzerinde negatif yönde etkilidir. }\end{array}$ \\
\hline $\begin{array}{l}\text { Amighini vd. } \\
(2017)\end{array}$ & $\begin{array}{l}53 \text { gelişmekte olan } \\
\text { ülke, 2003-2011 }\end{array}$ & $\begin{array}{l}\text { Panel veri analizi- } \\
\text { sistem GMM modeli }\end{array}$ & $\begin{array}{l}\text { Doğrudan yabancı yatırımların yurtiçi yatırımlar üzerinde pozitif etkileri } \\
\text { vardır. Ancak bu etkiler, doğrudan yabancı yatırımların türlerine göre } \\
\text { değişmektedir. Özellikle üretken faaliyetlerle uğraşan firmaların olduğu } \\
\text { sektörlerde doğrudan yabancı yatırımların pozitif etkisi daha güçlüdür. }\end{array}$ \\
\hline
\end{tabular}

Kaynak: Yazar tarafindan hazırlanmıştır. 
Kurul, Z. (2021), “Türkiye'de Doğrudan Yabancı Yatırım Girişleri ve Yurtiçi Yatırım

İlişkisi: Doğrusal Olmayan ARDL Yaklaşımı”, Sosyoekonomi, 29(49), 271-292.

\section{Türkiye'de Doğrudan Yabancı Yatırım Girişleri ve Yurtiçi Yatırım Gelişmeleri}

Türkiye'de doğrudan yabancı yatırım girişlerinin seyri Türkiye ekonomisinin yapısal dönüşümüyle ve dünya ekonomisindeki konjonktürel gelişmelerle ile birlikte açıklanabilir. Öncelikle Türkiye ekonomisi 1980 tarihinde yürürlüğe konan yeni ekonomik programla birlikte dış ticaret ve uluslararası sermaye akımları açısından yeni bir döneme girmiştir. 1980 yılında uygulanmaya başlayan istikrar programı, 1970'lerde uygulanan içe dönük ve korumacı politikaların geride bırakılmasını ve hem içte hem dışta piyasa serbestisini içermektedir. Bu serbestleşme hedefi doğrultusunda ilk olarak 1984 yılında ticaret kısıtları ve 1989 yılında sermaye hareketleri üzerindeki kısıtlar kaldırılmıştır. 1980 sonrası dönem, Türkiye ekonomisi açısından yapısal dönüşümün yaşandığı yılları temsil etmekle birlikte uygulanan model pek çok gelişmekte olan ülkenin aynı dönemde izlediği politikaları içermektedir. Aynı zamanda bu dönem dünya ekonomisindeki çevrimlere uyum sağlamaktadır. Dünya ekonomisindeki 1978-79 sonrası canlanma ve durgunluk dönemleri, diğer gelişmekte olan ülkeler gibi Türkiye ekonomisinin de gelişme temposunu etkilemiştir. Türkiye'de doğrudan yabancı yatırım girişlerindeki gelişmeler incelenirken hem Türkiye ekonomisindeki yapısal dönüşümün hem de küresel doğrudan yabancı yatırım girişlerindeki eğilimlerin dikkate alınması önem taşımaktadır.

Grafik 1'de görüldüğü gibi doğrudan yabanc1 yatırım girişleri, büyük ölçüde 1980'li yılların ortalarından itibaren artmaya başlamıştır 1974-1988 dönemindeki toplam doğrudan yabancı yatırım girişi \$324 milyon gibi oldukça düşük bir düzeyde iken 1980-1989 döneminde ise toplam doğrudan yabancı yatırım miktarı, \$1,02 milyar ulaşmıştır. 1992 yılında ise \$844 milyon seviyesinde gerçekleşerek 1980 sonrası dönemin yıl bazında en yüksek düzeyine ulaşmıştır. 1989 sonrası dış kaynak girişinin canlandığı ve dünya ekonomisinin genişlediği bir dönemin izlerinin yansıdığ yabancı yatırım çekmeye çalışan politikaların da etkisi vardır. Dünya ekonomisinin 19931997 yıllarındaki genişleme periyoduna rağmen 1993 yılında ülke içindeki ekonomik ve politik belirsizlikler ve döviz krizinin etkisiyle 1994 yılında \%27’lik bir azalma gerçekleşmiştir. Bu tarihten sonra ise çok büyük artışların yaşanmadığı ve 2001 yılındaki finansal krizin genişleme eğiliminin önünde bir engel oluşturduğu görülmektedir. 2001 krizinin hemen sonrasında doğrudan yabancı yatırım girişleri yaklaşık olarak \%50'lik bir düşüşle \$1,70 milyar seviyesinde gerçekleşmiştir. Avrupa Birliği’nin 2004 yılında Türkiye'nin üyeliğine dair görüşmelerinin olumlu etkisi ve kriz sonrası hızla uygulanmaya konan yabancı yatırımcıyı çekmeye yönelik teşvik politikaları ile birlikte doğrudan yabancı yatırım girişleri hızlı bir yükselişe geçmiş ve 2007 yılında \$22,04 milyar düzeyine çıkmıştır. Hızlı yükseliş eğilimi, doğrudan yabancı yatırım girişlerinin GSYH içindeki payı incelendiğinde de görülebilmektedir. 2002-2007 döneminde doğrudan yabancı yatırımların GSYH içindeki payı, 2002 öncesindeki \%1'in altındaki seviyeden yaklaşık \%4 seviyesine ulaşmaktadır. Bu süreçte özelleştirme politikalarının, şirket birleşme ve satın almaların ağırlık kazanmasının ve yabancı yatırımcıyı teşvik edecek yasal zemini oluşturma çabalarının özendirici olduğu görülmektedir. Türkiye ekonomisinde tarihsel zirvenin görüldüğü 2007 yılından itibaren dünya ekonomisindeki durgunluk doğrudan yabanc1 
yatırım girişlerinin azalmasına neden olmuştur. 2009 yılından itibaren toparlanan akımlar, 2018 yılına kadar kısa süreli artış ve azalışlar göstermiştir. Örneğin, 2015 yılındaki hızlı artıştan sonra yaklaşık \%27'lik bir azalma görülürken 2018 yılında yatırımlar yeniden artış eğilimine girmiştir. Sonuç olarak son yıllarda doğrudan yabancı yatırım girişlerinin GSYH içindeki payı \%1,5-2 aralığında dalgalanmakta ve bir önceki on yılın performansına yetişememektedir.

\section{Grafik: 1 \\ Doğrudan Yabancı Yatırım Girişleri (DYY)}

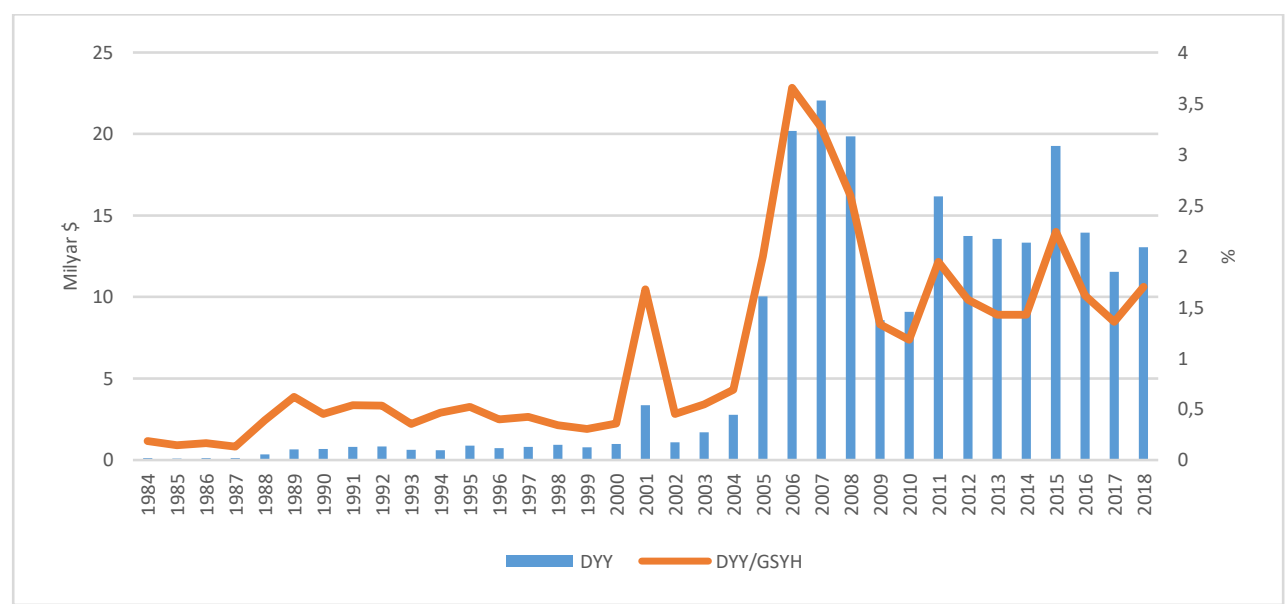

Kaynak: World Bank World Development Indicators Veri Tabanı, 2020.

Grafik 2, Türkiye'de 1984-2018 dönemindeki yurtiçi yatırımları temsilen seçilen brüt sabit sermaye oluşumunun seyrini göstermektedir. 1980'li yılların başına kadar pek çok gelişmekte olan ülkede olduğu gibi sabit sermaye oluşumu düşük ve durağan bir seyir izlemiştir. 1980 yılında uygulamaya konan yeni ekonomik programın etkileri ise 1980'lerin sonunda hissedilmeye başlanmıştır. 1986 yılından itibaren artışa geçen ve 1998 yılında yaklaşık \$65 milyar seviyesine çıkan yurtiçi yatırımlar, Türkiye'nin aynı dönemde finansal serbestleşmeyi gerçekleştirerek dış kaynak sağlamasının bir sonucu olabilir. Aynı zamanda yeni ekonomik program çerçevesinde yurtiçi tasarrufları artırmaya yönelik olarak faiz oranı üzerindeki kısıtlamalar kaldırılmış ve piyasada belirlenen faiz oranları yoluyla fonların yeni gelişmekte olan bankacılık sektörüne aktarılması sağlanmıştır (Sağlam \& Yalta, 2011: 74). Bankacılık sisteminin ve sermaye piyasalarının iyileştirilmesine yönelik adımlar da özel sektörün krediye ulaşması kolaylaştırmış ve yurtiçi yatırımlar üzerinde pozitif yönde etkili olmuştur. Ancak 1997 Asya krizinin yayıldığı ve doğrudan Türkiye'nin 2001 ekonomik krizinin etkisinin hissedildiği 1998-2002 döneminde sermaye oluşumu göreli olarak azalmıştır. 2001 krizi sonrasında yeni makroekonomi politikaları devreye girmiş ve finansal piyasalar güçlendirilmeye çalışılmıştır. Özellikle bankacılık sisteminin daha güvenilir ve işlevsel hale gelmesi için yasal adımların atıldığı bu dönemde yurtiçi yatırımların yeniden 
artışa geçtiği görülmektedir. Aynı dönemde ülkeye giren doğrudan yabancı yatırımlardaki artış da sabit sermaye oluşumuna katkı sağlayabilecek etkenlerden biridir. 2008-2009 döneminde Küresel Finansal Kriz etkisiyle yavaşlayan sabit sermaye oluşumu, hızla toparlanarak 2013 yılında tarihi zirvesi olan \$271 milyar seviyesine ulaşmıştır. Bu artışta hem kriz sonrası toparlanmanın hem de iyi seyreden makroekonomik göstergelerin etkili olabileceği düşünülmektedir. 2014-2018 döneminde ise sabit sermaye oluşumu artış eğilimini geride bırakmış ve \%15 düzeyinde bir azalış göstermiştir. Genel hatlarıyla Türkiye'de sabit sermaye yatırımları 2002 yılından sonra ciddi bir artış yaşamakla birlikte ekonominin konjonktürel gelişmelerine bağlı olarak iniş ve çıkışlar sergilemektedir. Sabit sermaye oluşumunun GSYH içindeki payı incelendiğinde de 1984-2018 dönemi boyunca \%15-30 aralığında dalgalandığı görülmektedir. Türkiye ekonomisinde uzun yıllardır değişmeyen düşük tasarruf oranı, sınırlı verimlilik artışı, ekonominin borçlanmaya dayalı finansman ve tüketime dayanan harcama yapısı gibi nedenlerle sabit sermaye yatırımları göreceli olarak düşük kalmaktadır.

Grafik: 2

Sabit Sermaye Oluşumu (SSO)

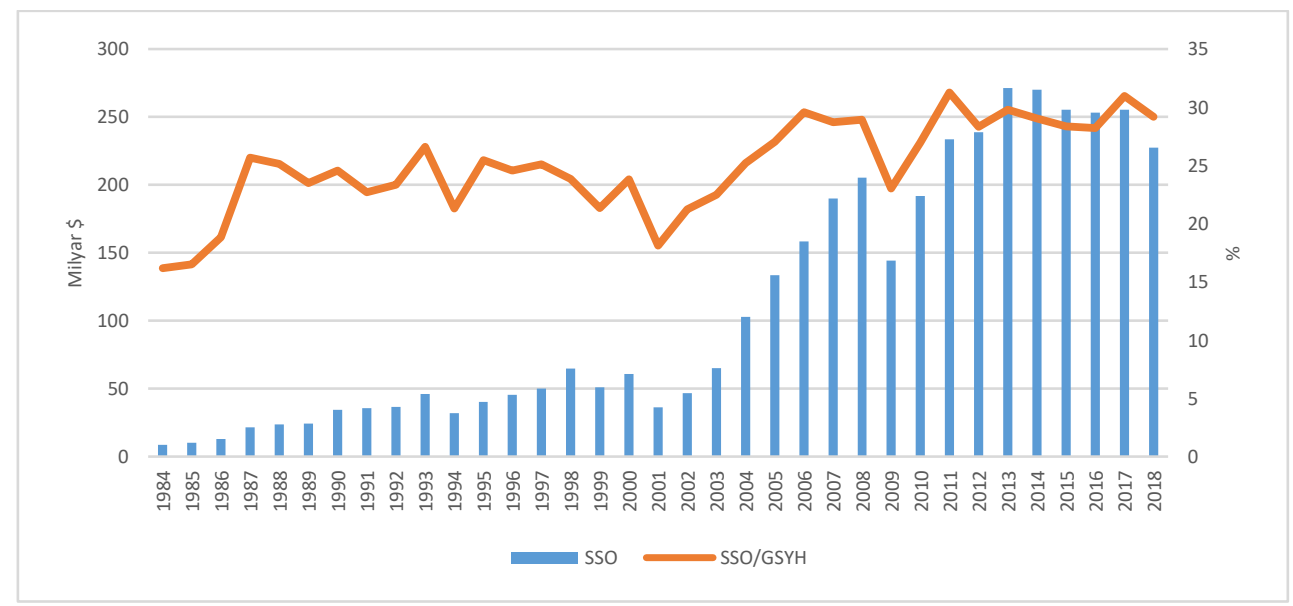

Kaynak: World Bank World Development Indicators Veri Tabanı, 2020.

\section{Yöntem ve Veri}

Daha önceki ampirik çalışmaların örtük varsayımı doğrudan yabancı yatırımların yurtiçi yatırımlar üzerindeki etkisinin simetrik olduğudur. Bir başka deyişle, pozitif ve negatif doğrudan yabancı yatırım şoklarının yurtiçi yatırımlar üzerindeki etkileri arasında büyüklük olarak bir fark yoktur. Bu çalışma, bu tür bir örtük varsayımdan kaçınarak olası asimetrik etkiyi dikkate almaktadır. Bu çalışmada asimetrik etkileri tespit etmek amacıyla Shin vd. (2014)'in geliştirdiği doğrusal olmayan ARDL yöntemine başvurulmaktadır. Doğrusal olmayan ARDL yaklaşımı, Pesaran vd. (2001)'in doğrusal ARDL yaklaşımını 
temel almaktadır. Buradan hareketle genel bir ARDL (n, m) gösterimi aşağıdaki şekilde ifade edilmektedir:

$$
\Delta y_{t}=\alpha+\delta y_{t-1}+\theta x_{t-1}+\sum_{i=1}^{n-1} \varphi_{i} \Delta y_{t-i}+\sum_{i=0}^{m-1} \rho_{i} \Delta x_{t-i}+\varepsilon_{t}
$$

(1) numaralı denklemde $\Delta$ birinci fark operatörüdür. $\alpha, \delta, \theta, \varphi_{i}, \rho_{i}$ tahmin parametreleri, $n$ ve $m$ optimal gecikme uzunluklarıdır. Bu denklemde eğer $\delta=\theta=0$ ise teorik olarak $y$ ve $x$ arasında bir eş bütünleşme ilişkisi yoktur. Dolayısıyla uzun dönem ilişkisinin olup olmadığına karar vermek için bir test istatistiğine ihtiyaç vardır. Pesaran vd. (2001), (1) numaralı denklemden bir FPSs istatistiği elde etmiş ve asimptotik kritik değerleri sunmuştur. Pesaran vd. (2001), düşük kritik sınır değeri ve yüksek kritik sınır değeri olmak üzere iki farklı asimptotik kritik değer kümesi oluşturmuştur. Eş bütünleşme ilişkisinin olup olmadığına kara vermek içi bu kritik değerlere göre bir karşılaştırma yapılmaktadır. Eğer Fistatistiği yüksek kritik sınır değerinden büyük ise eş bütünleşmenin olmadığını ifade eden boş hipotez reddedilmektedir ${ }^{3}$.

Doğrusal ARDL modelinin pek çok açıdan diğer geleneksel eş bütünleşme yaklaşımlarına göre avantajları olduğu kabul edilmektedir. Modelin en önemli avantajı, değişkenler ikinci dereceden bütünleşik olmamak kaydıyla her biri farklı bütünleşme derecelerinde olsalar bile (I(0), I(1) ya da kesirli bütünleşik dereceli olmak gibi) eş bütünleşme testinin yapılabilmesidir. Doğrusal ARDL modelinin avantajlarını kullanarak olası asimetrik etkileri göstermek amaciyla Shin vd. (2014) doğrusal olmayan ARDL modelini geliştirmiştir. Doğrusal olmayan ARDL modeli, eş bütünleşmenin ve asimetrik doğrusal olmama özelliklerinin bir arada modellenebilmesine olanak sağlamakta ve ayrıca diğer geleneksel eş bütünleşme teknikleri ile karşılaştırıldığında küçük örneklemlerde hata düzeltme mekanizmasını genişleterek daha iyi bir performans göstermektedir (Shahzad vd., 2017: 215; Jareno vd., 2020: 4).

Bu modelde öncelikle açıklayıcı değişken $x_{t}$ aşağıdaki şekilde ayrıştırılmaktadır.

$$
x_{t}=x_{0}+x_{t}^{+}+x_{t}^{-}
$$

Burada $x_{t}^{+}$ve $x_{t}^{-}$, x değişkenindeki pozitif ve negatif değişimlerin kısmı toplam süreçleridir ve şu şekilde elde edilmektedirler:

$$
\begin{aligned}
& x_{t}^{+}=\sum_{j=1}^{t} \Delta x_{j}^{+}=\sum_{j=1}^{t} \max \left(\Delta x_{j}, 0\right) \\
& x_{t}^{+}=\sum_{j=1}^{t} \Delta x_{j}^{-}=\sum_{j=1}^{t} \min \left(\Delta x_{j}, 0\right)
\end{aligned}
$$

Dolayısıyla doğrusal olmayan uzun dönem ilişki,

$$
y_{t}=\beta^{+} x_{t}^{+}+\beta^{-} x_{t}^{-}+u_{t}
$$

\footnotetext{
Sonuçların güvenilirliği açısından Banerjee vd. (1998)'in ortaya koyduğu $t_{B D M}$ istatistiği de kontrol edilebilir. Bu testte boş hipotez $\delta=0$, alternatif hipotez $\delta<0$ şeklinde tanımlanmıştır.
} 
denklemiyle ifade edilmektedir. (5) numaralı denklemde $\beta^{+}$ve $\beta^{-}, x_{t}$ 'teki pozitif ve negatif değişimlere ait uzun dönem asimetrik parametrelerdir. Son aşamada (1) ve (5) numaralı denklemeler birleştirilerek aşağıdaki doğrusal olmayan ARDL (n, m) denklemi elde edilmektedir:

$\Delta y_{t}=\alpha+\delta y_{t-1}+\theta^{+} x_{t-1}^{+}+\theta^{-} x_{t-1}^{-}+\sum_{i=1}^{n-1} \varphi_{i} \Delta y_{t-i}+\sum_{i=0}^{m-1}\left(\rho_{i}^{+} \Delta x_{t-i}^{+}+\rho_{i}^{-} \Delta x_{t-i}^{-}\right)+\varepsilon_{t}$

(6) numaralı denklemde $\theta^{+}$ve $\theta^{-}$, asimetrik ve gecikmesi dağıtılmış parametrelerdir. Aşağıda verilen (7) numaralı denklem ise ilişkili uzun dönem parametrelerini göstermektedir.

$$
\beta^{+}=-\frac{\theta^{+}}{\delta} \text { ve } \beta^{-}=-\frac{\theta^{-}}{\delta}
$$

Yukarıdaki modellemeye dayanarak ampirik analiz üç aşamadan oluşmaktadır. İlk olarak zaman serilerinin durağanlık testleri yapılmakta ve değişkenlerin bütünleşme dereceleri tespit edilmektedir. İkinci aşamada denklem (6) tahmin edilmekte ve değişkenlerin doğrusal olmayan bir biçimde eş bütünleşik olup olmadığına bakılmaktadır. Son olarak, eğer eş bütünleşme ilişkisi varsa bağımlı değişkenin asimetrik tepkileri tahmin edilmektedir. Uzun ve kısa dönem asimetrinin olup olmadığına Wald testi ile karar verilmektedir.

$\mathrm{Bu}$ çalışmada doğrudan yabancı yatırımlar ve yurtiçi yatırımlar arasındaki ilişki 1984-2018 dönemini kapsayan yıllık veriler kullanılarak analiz edilmektedir. Çalışmada kullanılan tüm veriler World Bank (2020), World Development Indicators veri tabanından elde edilmiştir. Yurtiçi yatırımları temsil etmek üzere sabit sermaye oluşumu verisi kullanılmıştır. Sabit sermaye oluşumu (SSO) ve doğrudan yabancı yatırım girişlerinin (DYY) her ikisi de GSYH'nin oranı olarak alınmış ve kontrol değişkenleri olarak ekonomik büyüme (BUY) ve ticarete açıklık (TA) değişkenleri kullanılmıştır. Kontrol değişkenlerinin seçiminde edilmesinde ampirik literatürdeki çok değişkenli çalışmalardan yararlanılmış ve sabit sermaye oluşumu üzerinde etkili oldukları düşünülen sınırlı sayıda değişken ele alınmıştır ${ }^{4}$. Kontrol değişkenlerinden ekonomik büyüme, GSYH'deki yıllık yüzde değişim oranı ile ölçülürken ticarete açıklık toplam ithalat ve ihracatın GSYH içindeki payı ile temsil edilmiştir. Değişkenlerin tanımlayıcı istatistikleri Tablo 2'de gösterilmektedir. SSO, DYY, BUY ve TA değişkenleri GSYH'nin yüzde oranı olarak sırasıyla 24,998, 1,057, 4,765 ve 43,706 ortalama değere sahiptirler. Değişkenler arasında standart sapması en yüksek olan TA; en düşük olan DYY'dir. Değişkenlerden yalnızca SSO ve TA normal dağılım özellikleri göstermektedir.

4 Çok değişkenli çalış̧malarda yurtiçi yatırımları etkileyen faktörler arasında çoğunlukla büyüme, kamu harcamaları, bütçe dengesi, ticarete açıkllk, enflasyon, döviz kuru, finansal gelişmişlik (Ndikumana, 2005; Apergis vd., 2006; Ndikumana ve Verick, 2008; Adams, 2009) değişkenlerine yer verilmektedir. Morrissey ve Udomkerdmongkol (2012) ve Farla vd. (2014) ise kurumsal faktörleri içeren modellere başvurmaktadır. 
Tablo: 2

Tanımlayıcı İstatistikler

\begin{tabular}{|c|c|c|c|c|c|c|c|}
\hline Değişkenler & Ortalama & Standart sapma & Minimum & Maksimum & Ĕgiklik & Basıklkk & Jarque-Bera \\
\hline SSO & 24,998 & 3,930 & 16,180 & 31,268 & $-0,495$ & 2,628 & 1,92 \\
\hline DYY & 1,057 & 0,906 & 0,131 & 3,653 & 1,178 & 3,743 & $8,42^{* *}$ \\
\hline BUY & 4,765 & 4,363 & $-5,962$ & 11,113 & $-1,012$ & 3,246 & $6,38^{* *}$ \\
\hline TA & 43,706 & 8,159 & 29,414 & 60,402 & $-0,213$ & 2,034 & 3,31 \\
\hline
\end{tabular}

Not: Jarque-Bera testi için boş hipotez: $H_{0}$ : Seri normal dă̆llmaktadır.

\section{Ampirik Bulgular}

Ampirik analizin ilk aşamasında tüm değiş̧enler için birim kök testleri yapılmıştır. Bu çalışmada üç tip doğrusal birim kök testine başvurulmuştur: Augmented Dickey Fuller (ADF) birim kök testi, Phillips-Peron birim kök testi ve Elliott, Rothenberg ve Stock (ERS) testi. Birim kök testlerinden elde edilen sonuçlar Tablo 3 ’te gösterilmektedir.

Tablo: 3

\section{Doğrusal Birim Kök Test Sonuçları}

\begin{tabular}{|c|c|c|c|c|c|c|}
\hline & \multicolumn{2}{|c|}{ ADF } & \multicolumn{2}{c|}{ PP } & \multicolumn{2}{c|}{ ERS } \\
\hline Değişkenler & Düzey & 1. Fark & Düzey & 1. Fark & Düzey & 1.Fark \\
\hline SSO & $-2,617$ & $-4,857^{* * *}$ & $-2,794^{*}$ & $-7,943^{* * * *}$ & $-2,719$ & $-4,013^{* * *}$ \\
\hline DYY & $-2,050$ & $-5,317^{* * *}$ & $-1,990$ & $-5,347^{* * * *}$ & $-3,084^{*}$ & $-4,977^{* * *}$ \\
\hline BUY & $-6,213^{* * *}$ & $-9,986^{* * *}$ & $-6,247^{* * *}$ & $-12,154^{* * * *}$ & $-3,428^{* * * *}$ & $-4,257^{* * *}$ \\
\hline TA & $-1,191$ & $-5,300^{* * *}$ & $-0,936$ & $-5,313^{* * *}$ & $-3,093^{* * *}$ & $-3,882^{* * *}$ \\
\hline
\end{tabular}

Notlar: ADF testi için boş hipotez: $H_{0}$ : Seriler dură̆an değildir. PP testi için boş hipotez: $H_{0}$ : Serilerde birim kök vardır. ERS testi için boş hipotez: $H_{0}$ : Seriler durağan değildir. *, **ve *** sırasıyla \%10, \%5 ve \%1 anlamlılık düzeylerini göstermektedir. Optimal gecikmeler Akaike gecikme uzunluğu seçim kriterine göre seçilmiştir. Tüm testler için sabit terimli modelin sonuçları verilmiştir.

Doğrusal birim kök test sonuçlarına göre hem sabit sermaye oluşumu (SSO) hem de doğrudan yabancı yatırım girişleri (DYY) düzeylerinde durağan olmayıp, birinci farklarında durağandır. Ekonomik büyüme değişkeni (BUY) tüm durağanlık testlerine göre düzeyinde durağandır. Ticarete açıklık değişkeni (TA) ise ADF ve PP testlerine göre birinci farkı alındığında durağan hale gelirken ERS testine göre düzeyinde durağandır. Farklı durağanlık testleri değişkenlerin hiçbirinin I(2) ya da daha yüksek dereceden bütünleşik olmadığını göstermektedir. Dolayısıyla ARDL yaklaşımının gerektirdiği diğer tüm testler uygulanabilir hale gelmektedir.

Doğrusal olmayan ARDL tahminine geçmeden önce serilere gelen şokların doğrusal olmayan dizilimdeki etkilerinin görülebilmesi amacıyla MTAR modele dayanan Enders ve Granger (1998), ESTAR modele dayanan Kapetanious vd. (2003) ve Hu ve Chen (2016) testleri yapılmıştır. Doğrusal olmayan birim kök testlerinin sonuçları Tablo 4'te sunulmaktadır.

EG (1998) test sonuçlarına göre sabit terimli modelde yalnızca büyüme değişkeni, doğrusal olmayan asimetrik bir durağan sürece sahip olmakla birlikte sabit terim ve trend içeren modelde tüm seriler doğrusal olmayan asimetrik bir durağan sürece sahiptir. KSS (2003) testi ise hem sabit terim hem de sabit terim ve trend içeren model için yalnızca büyüme değişkenin doğrusal olmayan ESTAR sürecine sahip olduğunu göstermektedir. Son 
olarak Hu ve Chen (2016) testine göre sabit terim içeren modelde yalnızca büyüme serisi doğrusal olmayan durağan ESTAR sürece sahipken, sabit terim ve trend içeren modelde tüm seriler doğrusal olmayan ESTAR sürece sahiptir.

\section{Tablo: 4}

\section{Doğrusal Olmayan Birim Kök Testleri}

\begin{tabular}{|c|c|c|c|c|c|c|}
\hline \multirow[b]{2}{*}{ Değișkenler } & \multicolumn{2}{|c|}{ EG (1998) } & \multicolumn{2}{|c|}{ KSS (2003) } & \multicolumn{2}{|c|}{ Hu ve Chen (2016) } \\
\hline & Sabit & Sabit ve Trend & Sabit & Sabit ve Trend & Sabit & Sabit ve Trend \\
\hline SSO & 3,707 & $6,352 *$ & $-2,102$ & $-2,314$ & 9,317 & $15,592 * *$ \\
\hline DYY & 3,310 & $5,828 *$ & $-1,596$ & $-1,542$ & 4,388 & $13,074 *$ \\
\hline BUY & $9,397 * * *$ & $9,206 * * *$ & $-5,393 * * *$ & $-5,381 * * *$ & $39,871 * * *$ & $40,257 * * *$ \\
\hline TA & 1,402 & $8,172 * *$ & $-1,591$ & $-3,914$ & 4,353 & $22,638^{* * * *}$ \\
\hline \multicolumn{7}{|c|}{ Kritik Değerler } \\
\hline$\% 10$ & 3,84 & 5,41 & $-2,66$ & $-3,13$ & 10,12 & 12,42 \\
\hline$\% 5$ & 4,73 & 6,52 & $-2,93$ & $-3,40$ & 11,86 & 14,39 \\
\hline$\% 1$ & 6,85 & 9,14 & $-3,48$ & $-3,13$ & 15,62 & 18,62 \\
\hline
\end{tabular}

Not: EG (1998), KSS (2003) ve Hu ve Chen (2016) testleri için boş hipotez: $H_{0}$ : Birim kök vardır. *, ** ve *** siraslyla \%10, \%5 ve \%1 anlamlllk düzeylerini göstermektedir. Optimal gecikmeler, Akaike gecikme uzunluğu seçim kriterine göre seçilmiştir.

Ayrıca, serilerin durum bağımlı (state dependent) doğrusal olmama ve yapısal kırılma özelliklerinin test edilmesinde Omay ve Yıldırım (2014) tarafından geliştirilen OY (2014) testine başvurulmuştur. OY (2014) testi, KSS (Kapetanious vd., 2003) ve LNV (Leybourne vd., 1998) testlerinin bir birleşimi olarak hem ESTAR fonksiyonuna dayalı olarak doğrusal olmayan uyarlanmaya hem de aşamalı bir yapısal kırılmaya izin vermektedir. OY (2014) testinin sonuçları Tablo 5'te gösterilmiştir. Test sonucuna göre birim kök boş hipotezi (doğrusal durağan olmama) sabit sermaye oluşumu serisinin ham veri modeli haricinde reddedilememektedir. Sabit sermaye oluşumu dışındaki seriler doğrusal olmayan trend ve sabit terim etrafında doğrusal olmayan ve durağan bir sürece sahip değildir.

Tablo: 5

\section{OY(2014) Testi Sonuçları}

\begin{tabular}{|c|c|c|c|}
\hline & \multicolumn{3}{|c|}{ OY (2014) } \\
\hline Değiškenler & Ham Veri & Sabit & Sabit ve Trend \\
\hline SSO & $-3,941^{*}$ & $-2,587$ & $-1,369$ \\
\hline DYY & $-1,559$ & $-1,313$ & $-1,260$ \\
\hline BUY & $-3,086$ & $-3,538$ & $-3,552$ \\
\hline TA & $-3,652$ & $-2,380$ & $-2,402$ \\
\hline
\end{tabular}

Not: $O Y$ (2014) testi için boş hipotez: $H_{0}$ : Birim kök vardır. *, ** ve *** sırasıly \% \%, \%5 ve \%1 anlamlılık düzeylerini göstermektedir.

Birim kök testleri yapıldıktan sonra doğrusal olmayan ARDL modeline daha güçlü bir dayanak oluşturmak için serilerin doğrusal olmama özellikleri Broock vd. (1996) tarafından geliştirilen BDS istatistiği ile tespit edilmeye çalışılmıştır. Tablo 6'daki sonuçlara göre ekonomik büyüme (BUY) değişkeni haricinde seriler özdeş ve bağımsız bir dağılıma sahip değildirler. Dolayısıyla doğrudan yabancı yatırımlar ve yurtiçi yatırımlar arasındaki doğrusal olmayan ilişkiyi belirleyebilmek için doğrusal olmayan bir model ile devam edilebilmektedir. 
Tablo: 6

BDS Testi Sonuçları

\begin{tabular}{|cccccc|}
\hline & \multicolumn{5}{c|}{ BDS İstatistiği } \\
\hline Değişkenler & $\mathrm{m}=2$ & $\mathrm{~m}=3$ & $\mathrm{~m}=4$ & $\mathrm{~m}=5$ & $\mathrm{~m}=6$ \\
\hline SSO & $0,067^{* * *}$ & $0,090^{* * *}$ & $0,121^{* * *}$ & $0,130^{* * * *}$ & $0,126^{* * * *}$ \\
\hline DYY & $0,051^{* *}$ & $0,081^{* *}$ & $0,096^{* *}$ & $0,106^{* *}$ & $0,143^{* * *}$ \\
\hline BUY & $-0,014$ & $-0,019$ & $-0,025$ & $-0,019$ & $-0,017$ \\
\hline TA & $0,103^{* * *}$ & $0,179^{* * *}$ & $0,245^{* * *}$ & $0,284^{* * *}$ & $0,299^{* * * *}$ \\
\hline
\end{tabular}

Not: BDS testi için boş hipotez: $H_{0}$ : seri özdeş ve bağımsız dağllmaktadır. *, ** ve *** sırasılyla \%10, \%5 ve \%1 anlamlılı düzeylerini göstermektedir.

$\mathrm{Bu}$ aşamadan sonra doğrusal olmayan ARDL modeli tahmin edilmekte ve değişkenler arasında uzun dönem ilişkisinin var olup olmadığı belirlenmektedir. Bu kısımda ampirik analiz iki kısma ayrılmaktadır. Öncelikle ana model olan çok değişkenli model çerçevesinde tahminler yapılmakta ve daha sonra sağlamlık kontrolü için iki değişkenli bir model kurularak yalnızca doğrudan yabancı yatırım girişleri ve sabit sermaye oluşumu arasındaki uzun dönem ilişkisi incelenmektedir.

\section{1 Çok Değişkenli Modelde Doğrusal Olmayan ARDL Tahminleri}

Bu kısımda doğrudan yabancı yatırım girişleri ve sabit sermaye oluşumu arasındaki ilişki, doğrudan yurtiçi yatırımlar ile etkileşimi olan iki kontrol değişkeni ile birlikte tahmin edilmiştir. Doğrudan yabancı yatırımlar ve sabit sermaye oluşumu arasındaki ilişkinin simetrik olduğu varsayımından uzaklaşmak için doğrudan yabancı yatırım girişlerindeki toplam değişim, pozitif ve negatif değişim olarak iki ayrı kısmi toplama ayrılmıştır. Yalnızca doğrudan yabancı yatırım girişlerinin asimetrik bir etkiye sahip olup olmadığını incelendiği için kontrol değişkenleri modele deterministik değişkenler olarak eklenmiştir. Bu varsayımlar altında aşağıdaki doğrusal olmayan ARDL $(n, m)$ modeli tahmin edilmiştir.

$$
\begin{aligned}
& \Delta S S O_{t}=\alpha+\delta S S O_{t-1}+\theta^{+} D D Y_{t-1}^{+}+\theta^{-} D D Y_{t-1}^{-}+\omega X_{t}+\sum_{i=1}^{n-1} \varphi_{i} \Delta S S O_{t-i}+ \\
& \sum_{i=0}^{m-1}\left(\rho_{i}^{+} \Delta D Y Y_{t-i}^{+}+\rho_{i}^{-} \Delta D Y Y_{t-i}^{-}\right)+\varepsilon_{t}
\end{aligned}
$$

Çok değişkenli doğrusal olmayan ARDL modelinin tahmin sonuçları Tablo 6'da sunulmaktadır. Tahmin sonuçlarına göre eş bütünleşme test istatistikleri (FPSs ve $t_{\mathrm{BDM}}$ ) doğrudan yabancı yatırım girişleri ile sabit sermaye oluşumu arasında uzun dönemli bir ilişkiye işaret etmektedir. Asimetrik bir ilişkinin varlığı altında Wald testi sadece uzun dönemde bir asimetri olduğunu göstermektedir. Elde edilen sonuçlara göre doğrudan yabancı yatırım girişleri ile sabit sermaye oluşumu arasındaki uzun dönem asimetrik katsayılar $\left(D Y Y^{p}=2.881\right)$ ve $\left(D Y Y^{n}=-2.246\right)$ sirasıly $\% 1$ ve $\% 5$ düzeyinde anlamlıdır. Doğrudan yabancı yatırım girişlerinde \%1'lik bir pozitif değişim (artış), sabit sermaye oluşumunda \%2.881'lik bir artışa neden olurken \%1'lik bir negatif değişim (azalış), \%2.246'lik bir azalışa yol açmaktadır. Bir başka ifadeyle, sabit sermaye oluşumundaki büyüme, doğrudan yabancı yatırım girişlerindeki pozitif değişimden (artıştan) daha büyük 
bir oranda etkilenmektedir ${ }^{5}$. Kısa dönem tahmin sonuçları incelendiğinde ise Wald testi, kısa dönem asimetrinin olmadığına işaret etmektedir.

Tablo: 6

Çok Değişkenli Modelde Doğrusal Olmayan ARDL Tahmin Sonuçları

\begin{tabular}{|c|c|c|c|}
\hline Bağımlı değişken: $\Delta \mathrm{SSO}$ & Katsayı & t-istatistiği & p-değeri \\
\hline Sabit & $19,508^{* * * *}$ & 3,99 & 0,001 \\
\hline $\mathrm{DYY}_{\mathrm{t}-1}$ & $-0,837 * * *$ & $-4,10$ & 0,001 \\
\hline $\mathrm{DYY}_{\mathrm{t}-1} \mathrm{p}^{\mathrm{s}}$ & $2,404 * *$ & 2,37 & 0,029 \\
\hline $\mathrm{DYY}_{\mathrm{t}-1}{ }^{\mathrm{n}}$ & $1,880^{*}$ & 1,77 & 0,094 \\
\hline$\Delta \mathrm{SSO}_{\mathrm{t}-1}$ & 0,150 & 1,23 & 0,236 \\
\hline$\Delta \mathrm{SSO}_{\mathrm{t}-2}$ & 0,107 & 1,21 & 0,241 \\
\hline$\Delta \mathrm{DYY}_{\mathrm{t}-\mathrm{l}}^{\mathrm{p}}$ & $-1,805^{*}$ & $-1,96$ & 0,066 \\
\hline$\Delta \mathrm{DYY}_{\mathrm{t}-1 \mathrm{n}}^{\mathrm{n}}$ & $-0,591$ & $-0,58$ & 0,569 \\
\hline$\Delta \mathrm{DYY}_{\mathrm{t}-2^{\mathrm{p}}}$ & 0,667 & 0,68 & 0,504 \\
\hline$\Delta \mathrm{DYY}_{\mathrm{t}-2^{\mathrm{n}}}$ & 0,743 & 0,78 & 0,444 \\
\hline BUY & $0,428 * * *$ & 6,61 & 0,000 \\
\hline TA & $-0,045$ & $-1,08$ & 0,292 \\
\hline Eş bütünleşme test istatistikleri & \multicolumn{3}{|c|}{ FPSS $=6,201 * * * t_{\text {BDM }}=-4,098 * * *$} \\
\hline Uzun dönem asimetrik katsayılar & \multicolumn{3}{|c|}{$\mathrm{UD}_{\mathrm{DYY}}^{\mathrm{p}}=2,871^{* * *} \mathrm{UDDYY}^{\mathrm{n}}=-2,246 * *$} \\
\hline Uzun ve kısa dönem asimetri testleri & \multicolumn{3}{|c|}{$\mathrm{W}_{\mathrm{UD}, \mathrm{DYY}}=5,095^{* *} \mathrm{~W}_{\mathrm{KD}, \mathrm{DYY}}=2,945$} \\
\hline
\end{tabular}

Notlar: $p$ ve $n$ üst simgeleri pozitif ve negatif kismi toplamlarl ifade etmektedir. UD ${ }^{p}$ ve UD ${ }^{n}$ uzun dönem kismi toplamlarla iliş̧kili olan uzun dönem katsayllarl göstermektedir. $W_{U D}$ ve $W_{K D}$ uzun ve kasa dönem asimetriyi test eden Wald istatistikleridir. *, ** ve *** strastyla \%10, \%5 ve \%1 anlamlllk düzeylerini göstermektedir. Optimal gecikme uzunluğu Akaike seçim kriterine göre belirlenmiştir.

Tablo 6'da kontrol değişkenlerinin etkileri gözden geçirildiğinde ekonomik büyümenin sabit sermaye oluşumu üzerinde anlamlı bir pozitif etkisi olduğu görülmektedir. Bu sonuç literatürdeki bazı çalışmaların (Borensztein vd., 1998; Agrawal, 2000; Wang, 2010) bulguları ile uyumlu olup daha hızlı büyüyen ekonominin daha çok yatırım yapma eğiliminde olduğunu ortaya koymaktadır. Ticarete açıklık değişkeni ise istatistiksel olarak anlamlı değildir. Bu sonuç güçlü bir şekilde ticaret açıklığın yurtiçi yatırımlar üzerinde pozitif etkili olduğuna dair kanıt elde eden çalışmalardan (Balasubramanyam vd., 1996, Bleaney, 1996; Harrison, 1995; Salahuddin \& Islam, 2008; Wacziarg, 2001) farklılaşmaktadır. Ancak ülkelerin ticarete açıklıktan fayda sağlaması için teknolojik kısıtların aşılması ya da belirli kurumsal reformlar ve uygun makroekonomi yönetimi gibi bazı koşulların yerine getirilmesi gerektiğine dair çalışmaların (Bhattacharyya vd., 2009; Chang vd., 2009; Kim \& Lin, 2009) sonuçlarını da dikkate almak gerekmektedir.

5 Tahmin katsaylları, Denklem (8)'da verilen modele göre yorumlanmıştır. Denklem (8)'da değişkenlerin birinci farklarının alınmasıla elde edilen $\Delta$ terimleri yer almaktadır. Bu terimler logaritmik farklar ifade etmemekle birlikte değişkenlerin düzeylerine göre yapılacak bir değerlendirmenin yanlış olacağl dikkate alınarak uzun dönem asimetrik etkiler, değişkenlerdeki büyüme üzerinden yorumlanmıştır. 


\section{2 İki değişkenli Modelde Doğrusal Olmayan ARDL Tahminleri}

İki değişkenli modelde yalnızca doğrudan yabancı yatırım girişleri ve sabit sermaye oluşumu arasındaki eş bütünleş̧me ilişkisi dikkate alınmaktadır. Buna göre (8) numaralı denklemde verilen doğrusal olmayan ARDL $(n, m)$ modeli tahmin edilmiştir ${ }^{6}$.

$$
\begin{aligned}
& \Delta S S O_{t}=\alpha+\delta S S O_{t-1}+\theta^{+} D D Y_{t-1}^{+}+\theta^{-} D D Y_{t-1}^{-}+\sum_{i=1}^{n-1} \varphi_{i} \Delta S S O_{t-i}+ \\
& \sum_{i=0}^{m-1}\left(\rho_{i}^{+} \Delta D Y Y_{t-i}^{+}+\rho_{i}^{-} \Delta D Y Y_{t-i}^{-}\right)+\varepsilon_{t}
\end{aligned}
$$

Tablo: 7

\begin{tabular}{|c|c|c|c|}
\hline Bağımlı değişken: $\Delta$ SSO & Katsayı & t-istatistiği & p-değeri \\
\hline Sabit & $22,753 * * *$ & 4,76 & 0,000 \\
\hline $\mathrm{SSO}_{\mathrm{t}-1}$ & $-0,983 * * *$ & $-4,63$ & 0,000 \\
\hline $\mathrm{DYY}_{\mathrm{t}-1}^{\mathrm{p}}$ & $2,145^{*}$ & 2,02 & 0,055 \\
\hline DYY ${ }_{t-1}{ }^{n}$ & 1,238 & 1,06 & 0,298 \\
\hline$\Delta \mathrm{SSO}_{\mathrm{t}-1}$ & $-0,008$ & $-0,05$ & 0,962 \\
\hline$\Delta \mathrm{DYY}_{\mathrm{t}-1}^{\mathrm{p}}$ & $-0,201$ & $-0,14$ & 0,887 \\
\hline$\Delta \mathrm{DYY}_{\mathrm{t}-1}{ }^{\mathrm{n}}$ & 1,705 & 1,12 & 0,273 \\
\hline Eş bütünleşme test istatistikleri & \multicolumn{3}{|c|}{$\mathrm{F}_{\mathrm{PSS}}=7,396 * * \mathrm{t}_{\mathrm{BDM}}=-4,628 * *$} \\
\hline Uzun dönem asimetrik katsayılar & \multicolumn{3}{|c|}{$\mathrm{UD}_{\mathrm{DYY}}{ }^{\mathrm{P}}=2,183^{*} * \mathrm{UD}_{\mathrm{DYY}}{ }^{\mathrm{n}}=-1,259$} \\
\hline Uzun ve kısa dönem asimetri testleri & \multicolumn{3}{|c|}{$\mathrm{W}_{\mathrm{UD}}, \mathrm{DYY}=9,837 * * * \mathrm{~W}_{\mathrm{KD}}, \mathrm{DYY}=4,575 * *$} \\
\hline
\end{tabular}

Tek Değişkenli Modelde Doğrusal Olmayan ARDL Modelinin Tahmin Sonuçları

Notlar: $p$ ve $n$ üst simgeleri pozitif ve negatif kusmi toplamlarl ifade etmektedir. $U D^{p}$ ve UD ${ }^{n}$ uzun dönem kismi toplamlarla ilişkili olan uzun dönem katsayllarl göstermektedir. $W_{U D}$ ve $W_{K D}$ uzun ve kusa dönem asimetriyi test eden Wald istatistikleridir. *, ** ve *** surasıla \% $\%$, \%5 ve \%1 anlamlllk düzeylerini göstermektedir. Optimal gecikme uzunluğu Akaike seçim kriterine göre belirlenmiştir.

Tablo 7'de gösterilen eş bütünleşme test istatistiklerine ( $\mathrm{F}_{\mathrm{PSS}}$ ve $\mathrm{t}_{\mathrm{BDM}}$ ) göre doğrudan yabancı yatırım girişleri ile sabit sermaye oluşumu arasında $\% 5$ anlamlılık düzeyinde bir eş bütünleşme ilişkisi vardır. Kısa ve uzun dönem asimetrinin varlığının tespiti için ise Wald testi uygulanmıştır. Simetrik bir etkinin olduğunu ifade eden boş hipotez hem uzun hem de kısa dönem için reddedilmektedir. Dolayısıyla hem uzun hem de kısa dönemde doğrudan yabancı yatırım girişlerinin sabit sermaye oluşumu üzerindeki etkisi asimetriktir. Bir başka deyişle, sabit sermaye oluşumu, doğrudan yabancı yatırım girişlerindeki pozitif ve negatif değişimlere farklı büyüklükte tepkiler vermektedir. Ancak tahmin sonuçları, uzun dönem asimetrik katsayılardan yalnızca $\left(\mathrm{DYY} \mathrm{Y}^{\mathrm{p}}=2.183\right)^{\prime}$ 'nin istatistiksel olarak anlamlı olduğunu göstermektedir. Buna göre sabit sermaye oluşundaki büyüme yalnızca doğrudan yabancı yatırım girişlerindeki pozitif değişimden (artıştan) etkilenmektedir. Doğrudan yabancı yatırım girişlerindeki \%1'lik bir pozitif değişim (artış), sabit sermaye oluşumunda \%2.183 oranında bir artışa neden olmaktadır. Son olarak, Wald testi kısa dönemde doğrudan yabancı yatırım girişlerinin sabit sermaye oluşumu üzerindeki etkisinin asimetrik olduğuna işaret etmekle birlikte tahmin edilen kısa dönem asimetrik katsayılar istatistiksel olarak anlamlı değildir.

6 Doğrusal olmayan ARDL tahminlerinin tamamı Stata14 paketi üzerinden Stata için Marco Sunder tarafindan yazılan nardl komutu ile tahmin edilmiştir. Nardl komutu ile detaylı bilgi için bkz. <http://www.marcosunder.de/stata/> ve <http://www.greenwoodeconomics.com/>. 


\section{Sonuç}

Doğrudan yabancı yatırım girişlerinin özellikle gelişmekte olan ülkeler için büyük önem taşımasının nedenlerinden biri yurtiçi sermaye oluşumu üzerindeki etkisidir. Bu yönüyle doğrudan yabancı yatırımlar, yurtiçi sermaye oluşumunun dış kaynağı olma işlevini üstlenebilmekte ve kalkınmanın finansmanında belirleyici hale gelmektedir. Bu çalışma son yirmi yıldır önemli ölçüde doğrudan yabancı yatırım çeken bir gelişmekte olan ülke olan Türkiye'de doğrudan yabancı yatırım girişleri ile yurtiçi yatırımlar arasındaki ilişkiyi ortaya çıkarmayı amaçlamaktadır. Bu amaca yönelik olarak 1984-2018 dönemini kapsayan verilerle doğrusal olmayan ARDL modeli kullanılarak bir analiz yapılmıştır. Çalışmanın sonuçları, Türkiye'de doğrudan yabancı yatırımlar ve yurtiçi yatırımlar arasında asimetrik bir uzun dönem tamamlayıcılık ilişkisi olduğunu göstermektedir. Doğrudan yabancı yatırım girişler, uzun dönemde yurtiçi yatırımlar üzerinde etkilidir ancak bu etki, doğrudan yabancı yatırımlardaki pozitif ve negatif değişimlerde farklılaşmaktadır. Elde edilen bulgulara göre, çok değişkenli modelde sabit sermaye oluşumunun doğrudan yabancı yatırımlardaki pozitif değişime (artışa) verdiği tepki, negatif değişime (azalışa) verdiği tepkiden daha büyüktür. İki değişkenli modelde ise sabit sermaye oluşumu, yalnızca doğrudan yabancı yatırım girişlerindeki pozitif değişime (artışa) cevap vermektedir.

Bu çalışma, elde ettiği sonuçlarla Türkiye'de yurtiçi yatırımlarla doğrudan yabancı yatırımlar arasında asimetrik bir tamamlayıcılık ilişkisi bulunduğunu öne sürmektedir. Dolayısıyla doğrudan yabancı yatırım girişlerindeki büyüme, sermaye birikiminin artması için önemli bir dış finansman olanağı sunmaktadır. Çalışmanın sonuçları, politika yapıcıların doğrudan yabancı yatırımcıları ülkeye çekecek politikalara yönelmesi ve mevcut teşvik edici uygulamaları sürdürmesi açısından önem taşımaktadır. Bir ülkenin doğrudan yabancı yatırımları çekebilmesinin çeşitli yolları bulunmaktadır. Bu yollardan bazıları yatırımcılara güvenli bir yatırım ortamının sağlanmasına yöneliktir. Özellikle makroekonomik temellerin güçlendirilmesi ve istikrara kavuşturulması yabancı yatırımcılar açısından belirsizlikleri ortadan kaldırabilir ve uzun dönemli yatırım planlarının önünü açabilir. Bunun yanı sıra finansal gelişmişliği artırmaya yönelik adımlar yatırımcılara gerekli fonların sağlanmasına yardımcı olup yatırımcıların üretken sektörlerde yatırım yapmalarına olanak tanıyabilir. Bir diğer taraftan doğrudan yabancı yatırım girişlerini artması ülkedeki iş yapma kolaylığı ile ilgilidir. Bu nedenle politika yapıcıların izleyebileceği yollardan biri yatırımcılara iş yapma kolaylığı sağlayacak yasal ve kurumsal çerçevenin sunulmasıdır. İş süreçlerinin iyi tanımlanması ve kurallara dayalı hale getirilmesi, bürokratik işlem yükünün azaltılması, aşırı düzenlemelerden kaçınılması ve özellikle mülkiyet haklarının korunması hem yurtiçi hem de yabancı yatırımcılar için tercih edilebilir yatırım ortamı sunulmasına katkı sağlayabilecek uygulamalardır.

\section{Kaynaklar}

Adams, S. (2009), "Foreign Direct Investment, Domestic Investment, and Economic Growth in SubSaharan Africa", Journal of Policy Modeling, 31(6), 939-949. 
Kurul, Z. (2021), “Türkiye'de Doğrudan Yabancı Yatırım Girişleri ve Yurtiçi Yatırım İlişkisi: Doğrusal Olmayan ARDL Yaklaşımı”, Sosyoekonomi, 29(49), 271-292.

Agosin, M.R, \& R. Machado (2005), "Foreign Investment in Developing Countries: Does It Crowd in Domestic Investment?, Oxford Development Studies, 33(2), 149-162.

Agrawal, P. (2000), "Economic Impact of Foreign Direct Investment in South Asia", India and the WTO, 117.

Alfaro, L. \& A. Chanda \& S. Kalemli-Ozcan \& S. Sayek (2004), "FDI And Economic Growth: The Role of Local Financial Markets", Journal of International Economics, 64(1), 89-112.

Al-Sadiq, M.A.J. (2013), Outward Foreign Direct Investment and Domestic Investment: The Case of Developing Countries, (No. 13-52), International Monetary Fund.

Amighini, A.A. \& M.S. Mcmillan \& M. Sanfilippo, (2017), FDI and Capital Formation in Developing Economies: New Evidence From Industry-Level Data, (No. W23049), National Bureau of Economic Research.

Amsden, A.H. (2011), "Firm Ownership and Entrepreneurship", içinde: A. Szirmai \& W. Naudè \& M. Goedhuys (eds.), Entepreneurship, Innovation, and Economic Development, Oxford University Press, 65-77.

Apergis, N. \& C.P. Katrakilidis \& N.M. Tabakis (2006), "Dynamic Linkages Between FDI Inflows and Domestic Investment: A Panel Cointegration Approach", Atlantic Economic Journal, 34(4), 385-394.

Balasubramanyam, V.N. \& M. Salisu \& D. Sapsford (1996), "Foreign Direct Investment and Growth in EP and IS Countries", The Economic Journal, 106(434), 92-105.

Banerjee, A. \& J. Dolado \& R. Mestre (1998), "Error-correction Mechanism Tests for Cointegration in a Single-equation Framework", Journal of Time Series Analysis, 19(3), 267-283.

Bayar, Y. (2014), "Effects of Foreign Direct Investment Inflows and Domestic Investment on Economic Growth: Evidence From Turkey", International Journal of Economics and Finance, 6(4), 69-78.

Bhattacharyya, S. \& S. Dowrick \& J. Golley, (2009), "Institutions and Trade: Competitors or Complements in Economic Development?", Economic Record, 85(270), 318-330.

Bilgili, F. \& N.S.H. Tülüce \& İ. Doğan (2012), "The Determinants of FDI in Turkey: A Markov Regime-switching pproach", Economic Modelling, 29(4), 1161-1169.

Bleaney, M.F. (1996), "Macroeconomic Stability, Investment and Growth in Developing countries", Journal of Development Economics, 48(2), 461-477.

Borensztein, E. \& J. De Gregorio \& J.W. Lee (1998), "How Does Foreign Direct Investment Affect Economic Growth?”, Journal of International Economics, 45(1), 115-135.

Bosworth, B.P. \& S.M. Collins \& C.M. Reinhart (1999), "Capital Flows to Developing Economies: Implications for Saving and Investment”, Brookings Papers on Economic Activity, 1999(1), 143-180.

Broock, W.A. \& J.A. Scheinkman \& W.D. Dechert \& B. LeBaron (1996), “A test for Independence Based on The Correlation Dimension", Econometric Reviews, 15(3), 197-235.

Chang, R. \& L. Kaltani \& N.V. Loayza (2009), "Openness Can Be Good for Growth: The Role of Policy Complementarities”, Journal of Development Economics, 90(1), 33-49.

Chang, S.C. (2010), "Estimating Relationships Among FDI Inflow, Domestic Capital, and Economic Growth Using The Threshold Error Correction Approach", Emerging Markets Finance and Trade, 46(1), 6-15. 
Choi, C. (2004), "Foreign Direct Investment and Income Convergence”, Applied Economics, 36(10), 1045-1049.

De Mello, L.R. (1999), "Foreign Direct Investment-Led Growth: Evidence From Time Series and Panel Data", Oxford Economic Papers, 51(1), 133-151.

Enders, W. \& C.W.J. Granger (1998), "Unit-root Tests and Asymmetric Adjustment With An Example Using The Term Structure of Interest Rates", Journal of Business \& Economic Statistics, 16(3), 304-311.

Erdal, F. \& E. Tatoglu (2002), "Locational Determinants of Foreign Direct Investment In An Emerging Market Economy: Evidence From Tukey”, Multinational Business Review, 10, 21-27.

Eroglu, O. \& J. Hudson (1997), “The Effects of Foreign Capital Inflows in Turkey", Hacettepe University Journal of Economics and Administrative Sciences, 15(1).

Farla, K. \& D. De Crombrugghe \& B. Verspagen (2016), "Institutions, Foreign Direct Investment, and Domestic Investment: Crowding Out or Crowding In?”, World Development, 88, 19.

Fry, M.J. (1993), Foreign Direct Investment in a Macroeconomic Framework: Finance, Efficiency, Incentives and Distortions, (Vol. 1141). World Bank Publications.

Güven, S. (2001), “Sermaye Hareketlerinin Nedenleri, Etkileri ve Türkiye Örneği”, İktisat İşletme ve Finans, 16(185), 79-98.

Harrison, A. (1995), Openness and Growth: A Time-series, Cross-country Analysis for Developing Countries (No. w5221), National Bureau of Economic Research.

Hu, J. \& Z. Chen (2016), “A Unit Root Test Against Globally Stationary ESTAR Models When Local Condition Is Non-Stationary”, Economics Letters, 146, 89-94.

İnsel, A. \& N. Sungur (2003), "Effect of Capital Flows on Basic Macroeconomic Indicators: Evidence from Turkey, 1989 III-1999”, Türkiye Ekonomi Kurumu Tartışma Metni, 2003/8.

Jansen, K. (1995), "The Macroeconomic Effects of Direct Foreign Investment: The Case of Thailand", World Development, 23(2), 193-210.

Jareño, F. \& M. de la O González \& M. Tolentino \& K. Sierra (2020), "Bitcoin and Gold Price Returns: A Quantile Regression and NARDL Analysis”, Resources Policy, 67, 101666.

Jyun-Yi, W. \& H. Chih-Chiang (2008), "Does Foreign Direct Investment Promote Economic Growth? Evidence From a Threshold Regression Analysis", Economics Bulletin, 15(12), $1-10$.

Kapetanios, G. \& Y. Shin \& A. Snell (2003), "Testing For a Unit Root in the Nonlinear STAR Framework", Journal of Econometrics, 112(2), 359-379.

Kara, M.A. \& M. Kar (2005), "Yabancı Sermaye Çeşitlerinin Yatırımlar ve Tasarruflar Üzerine Etkilerinin Ekonometrik Analizi”, İktisat İsletme ve Finans, 20(228), 93-108.

Karagöz, K. (2007), “Türkiye'de Doğrudan Yabancı Yatırım Girişlerini Belirleyen Faktörler: 19702005", Journal of Yaşar University, 2(8), 929-948.

Kim, D.D.K. \& J.S. Seo (2003), “Does FDI Inflow Crowd Out Domestic Investment in Korea?", Journal of Economic Studies, 30(6), 605-622.

Kim, D.H. \& S.C. Lin (2009), "Trade and Growth at Different Stages of Economic Development", Journal of Development Studies, 45(8), 1211-1224. 
Kottaridi, C. \& T. Stengos (2010), "Foreign Direct Investment, Human Capital And Non-Linearities in Economic Growth", Journal of Macroeconomics, 32(3), 858-871.

Leybourne, S. \& P. Newbold \& D. Vougas (1998), "Unit Roots and Smooth Transitions", Journal of Time Series Analysis, 19(1), 83-97.

Lipsey, R.E. (2004), "Home-And Host-Country Effects of Foreign Direct Investment", içinde: R.E. Baldwin \& L.A. Winters (eds.), Challenges to Globalization: Analyzing the Economics, University of Chicago Press, 333-382.

Markusen, J.R. \& A.J. Venables (1999), "Foreign Direct Investment as a Catalyst for Industrial Development", European Economic Review, 43(2), 335-356.

Mišun, J. \& V. Tomšík (2002), "Foreign Direct Investment in Central Europe-Does It Crowd In Domestic Investment?", Prague Economic Papers, 11(1), 57-66.

Mody, A. \& A. Murshid (2002), “Growing Up with Capital Flows”, IMF Working Paper WP/02/75, Washington, DE: IMF.

Morrissey, O. \& M. Udomkerdmongkol (2012), “Governance, Private Investment and Foreign Direct Investment in Developing Countries", World Development, 40(3), 437-445.

Ndikumana, L. \& S. Verick (2008), "The Linkages Between FDI and Domestic Investment: Unravelling The Developmental Impact of Foreign Investment in Sub-Saharan Africa", Development Policy Review, 26(6), 713-726.

Ndikumana, L. (2005), "Financial Development, Financial Structure, and Domestic Investment: International Evidence”, Journal of International Money and Finance, 24(4), 651-673.

Omay, T. \& B. Araz-Takay \& A. Eruygur \& İ. Kilic (2013), "The Effects of Terrorist Activities on Foreign Direct Investment: Nonlinear Evidence From Turkey”, Review of Economics, 64(2), 139-158.

Omay, T. \& D. Yildirim (2014), "Nonlinearity and Smooth Breaks in Unit Root Testing", Econometrics Letters, 1(1), 2-9.

Pesaran, M.H. \& Y. Shin \& R.J. Smith (2001), "Bounds Testing Approaches to the Analysis of Level Relationship", Journal of Applied Econometrics, 16(3), 289-326.

Ramirez, M.D. (2010), "Is Foreign Direct Investment Productive in the Latin America Case? A Panel Co-integration Analysis, 1980-2002”, The International Trade Journal, 25(1), 35-73.

Sağlam, B.B. \& A.Y. Yalta (2011), "Dynamic Linkages Among Foreign Direct Investment, Public Investment and Private Investment: Evidence from Turkey", Applied Econometrics and International Development, 11(2), 71-82.

Salahuddin, M. \& M.R. Islam (2008), "Factors Affecting Investment in Developing Countries: A Panel Data Study", The Journal of Developing Areas, 42(1), 21-37.

Sayek, S. (2007), "FDI in Turkey: The Investment Climate and EU Effects", The Journal of International Trade and Diplomacy, 1(2), 105-138.

Shahzad, S.J.H. \& S.M. Nor \& R. Ferrer \& S. Hammoudeh (2017), “Asymmetric determinants of CDS Spreads: US Industry-level Evidence Through the NARDL Approach", Economic Modelling, 60, 211-230.

Shin, Y. \& B. Yu \& M. Greenwood-Nimmo (2014), "Modelling Asymmetric Cointegration and Dynamic Multipliers in a Nonlinear ARDL Framework", içinde: R.C. Sickles \& W.C. Horrace (eds.) Festschrift in Honor of Peter Schmidt, New York, NY, Springer, 281-314. 
Sun, H. (1998), “Macroeconomic Impact of Direct Foreign Investment in China: 1979-96”, World Economy, 21(5), 675-694.

Tang, S. \& E.A. Selvanathan \& S. Selvanathan (2008), "Foreign Direct Investment, Domestic Investment and Economic Growth in China: A Time Series Analysis", World Economy, 31(10), 1292-1309.

Titarenko, D. (2005), “The Influence of Foreign Direct Investment on Domestic Investment Processes in Latvia", MPRA Paper, 18192, University Library of Munich, Germany.

UNCTAD (2019), <https://unctad.org/en/publicationslibrary/wir2019_en.pdf>, 22.03.2020.

Wacziarg, R. (2001), Measuring the Dynamic Gains from Trade, The World Bank.

Wang, C. \& L. Yu (2007), "Do Spillover Benefits Grow with Rising Foreign Direct Investment? An Empirical Examination of the Case of China", Applied Economics, 39(3), 397-405.

Wang, M. (2010), "Foreign Direct Investment and Domestic Investment in the Host Country: Evidence From Panel Study", Applied Economics, 42(29), 3711-3721.

World Bank (2009), "Global Development Finance 2009: Charting A Global Recovery: Review, Analysis, and Outlook (English)", Global Development Finance, Washington, DC: World Bank.

World Bank (2020), <https://data.worldbank.org>, 01.03.2020. 